\title{
Elite Polarization in South Korea: Evidence from a Natural Language Processing Model
}

\author{
Seungwoo $\operatorname{Han}^{\star}$ (D) \\ Division of Global Affairs, Rutgers University, Newark, NJ, USA \\ *Corresponding author. Email: seungwoo.han@rutgers.edu
}

(Received 18 December 2020; revised 28 September 2021; accepted 8 November 2021)

\begin{abstract}
This study analyzes political polarization among the South Korean elite by examining 17 years' worth of subcommittee meeting minutes from the South Korean National Assembly's standing committees. Its analysis applies various natural language processing techniques and the bidirectional encoder representations from the transformers model to measure and analyze polarization in the language used during these meetings. Its findings indicate that the degree of political polarization increased and decreased at various times over the study period but has risen sharply since the second half of 2016 and remained high throughout 2020. This result suggests that partisan political gaps between members of the South Korean National Assembly increase substantially.
\end{abstract}

Keywords: political polarization; elite polarization; natural language processing; BERT; text classification; South Korea

\section{Introduction}

South Korea has experienced economic development and democratization in a relatively short period of time. However, Koreans' evaluation of Korean politics is negative. Koreans are particularly concerned about what they perceive as a growing polarization between liberal and conservative political parties. Indeed, this perception has been verified by previous studies, which have shown that South Korea's two major political parties are now characterized by high levels of internal ideological homogeneity and have increasingly diverged from one another over time (Ka 2014; Park et al. 2016). In this way, the South Korean situation meets the definition of political polarization, which can be defined as loss of the capacity for inter-party dialog and compromise and the recurrence of hostile confrontations and deadlock (McCarty, Poole, and Rosenthal 2006). In this study, political polarization refers specifically to the polarization of the political elites participating in party politics (Baldassarri and Gelman 2008). This is because political parties do not resolve but rather amplify social conflicts in Korean society (Cho and Lee 2021; Kwon 2020; Lee 2011; Lim et al. 2019).

(C) The Author(s), 2022. Published by Cambridge University Press on behalf of the East Asia Institute. This is an Open Access article, distributed under the terms of the Creative Commons Attribution licence (https://creativecommons.org/ licenses/by/4.0/), which permits unrestricted re-use, distribution, and reproduction in any medium, provided the original work is properly cited. 
In this way, the polarization of elites can drive polarization on a societal scale (Druckman, Peterson, and Slothuus 2013; Robison and Mullinix 2016; Banda and Cluverius 2018).

Despite its important role for representative democracy, public confidence in the National Assembly is low compared to other public institutions. A 2019 survey noted that public confidence in the National Assembly (19.7 percent) is rather low compared to institutions such as South Korea's central government (38.4 percent), court system (36.8 percent), police (36.5 percent), and prosecution (32.2 percent) (Statistics Korea 2020). Some scholars have suggested that this low level of public confidence in the National Assembly is a direct result of the disappearance of compromise and coexistence within National Assembly politics, which is reflected in the confrontation and deadlock between political parties (Yoo 2009; Seo 2016). As these hostile, polarizing confrontations between political parties continue and repeat, major legislation and policy issues become delayed, and law-making becomes more difficult and less effective (McCarty, Poole, and Rosenthal 2006; Gilmour 1995; Groseclose and McCarty 2001). Although it is easier for internally consistent majority ruling parties to garner the support necessary to pass legislative proposals, enacting such bills into law is more difficult when politics are polarized in this way (Krehbiel 1998; Brady and Volden 1998). This is a key issue, because as the productivity of politics decreases, distrust in politics increases, and the meaning and purpose of representative democracy fade as a result (Hibbing and Theiss-Morse 1995, 2002; Hetherington 2005; Theriault 2008). In short, although the expression and fierce contestation of political views is important to democracy, ideological differences between parties can widen to the point that confrontation and conflict intensify and productive debate or legislative work is impossible. Thus, it is very important for observers and policy-makers alike to determine the roots, extent, and consequences of political polarization, and to work to remedy it.

Since roll-call data were released from the second half of the 16th National Assembly, scholars have studied political polarization within the National Assembly using the Nominal Three-Step Estimation (NOMINATE) method proposed by Poole and Rosenthal (1985) (e.g., Jeon 2006; Lee and Lee 2008; Lee and Lee 2015). However, this approach only measures the outcome of votes on bills, not how polarization arises and affects the legislative process in detail. The current study aims to present empirical evidence of the polarization of South Korean political elites by analyzing subcommittee meeting minutes that actually reflect the legislative process, rather than the result of votes on the floor. Thus, it fills some gaps in the literature.

The subcommittee meeting minutes show how politicians from across the political spectrum use language to gain advantages in debates over bills, and they thus reflect the active, competitive use of language in the legislative process (Edelman 1985, 16). This study focuses primarily on the second subcommittee of the Legislation and Judiciary Committee because it examines the wording of all bills that have been reviewed by other committees. This study uses a natural language processing (NLP) model that learned the political language of 20 years of whole subcommittee meeting minutes to examine the minutes of the second subcommittee of the Legislation and Judiciary Committee from the 17th National Assembly through 20th National Assembly in their entirety and quantify changes in political polarization overtime. 
The classification model of the NLP technique learns sentences and words belonging to the two classes, and the trained model classifies the target text and measures its accuracy. The degree of this accuracy is calculated by measuring the polarization of political language. Its findings indicate that the degree of political polarization increased and decreased at various times over the study period but has risen sharply since the second half of 2016 and remained high through 2020. This suggests that partisan political gaps between members of the South Korean National Assembly increase substantially.

The use of neural network NLP techniques can complement previous studies and present different perspectives on analyzing political polarization. The current study also contributes to the literature by providing empirical evidence from South Korea, as most recent attempts to analyze ideology using neural network NLP techniques have been limited to Anglophone and European countries.

The remainder of the article is organized as follows. Section 2 reviews the literature on measuring political polarization and presents some theoretical discussion of language's relation to politics. Section 3 discusses this study's methodology. Section 4 discusses this study's data-that is, the subcommittee meeting minutesin more detail. Section 5 provides the results. Section 6 discusses the findings in some detail. Section 7 discusses the implications of the findings.

\section{Literature review}

Political polarization is not exclusively a South Korean problem; it is a growing global phenomenon (McCarty, Poole, and Rosenthal 2006; Singer 2016; Pew Research Center 2017; Banda and Cluverius 2018; Vachudova 2019). Political polarization has been studied mainly in the context of national-level politics in the United States (Abramowitz and Saunders 2008; Theriault 2008; Shor and McCarty 2011; Banda and Cluverius 2018). According to Binder (1999) and Fleisher and Bond (2004), the political polarization of national-level politics in the United States has intensified since the Democratic and Republic parties took on more sharply divisive and ideological identities in the 1980s and 1990s. They also found that cross-party voting has declined, as has the number of opposition members supporting the president's agenda. Furthermore, Layman and Carsey $(2000,2002)$ found that congressional candidates with increasingly ideological roll-call voting records are more likely to be elected or re-elected.

Although South Korea, unlike the United States, has a parliamentary system with multiple political parties, two major parties have occupied most seats in the South Korean National Assemblies since the 1990s (after democratization)-much like the United States, which only has two political parties. While South Korea's liberal-conservative dimension does not exactly match the liberal-conservative dimension in the United States party system, it has become very analogous to its party system in terms of the political parties' position on economic and redistribution policy (Hix and Jun 2009; Kang 2018; Kwak 1998). In addition, Korean political parties have developed toward a loosely centralized organization, rather than a catch-all organization (Han 2021). The cohesion of the two political parties has been somewhat large, even though their cohesion has been weakened compared to when 
they were led by two charismatic politicians, Kim Young-sam and Kim Dae-jung, the former presidents (Han 2021; Horiuchi and Lee 2008; Jeon 2014; Kim 2008). Both parties have a strong support base in that they developed based on regionalism: the Honam and Youngnam regions (Cho 1998; Kang 2016; Kwon 2004; Lee and Repkine 2020; Moon 2005).

Scholarly literature on political polarization in South Korea has appeared only recently. Lee (2011) gave empirical grounds for examining political polarization in the Korean context by analyzing changes in lawmakers and Korean citizens' ideological orientation. They found that polarization increased between politicians but was minimal between citizens, suggesting that polarization in Korean politics is driven by political elites. Similarly, Ka (2014) surveyed members of the 16th, 17th, 18th, and 19th National Assemblies and found that the ideological gaps between them widened over this period. Lee and Lee (2015) analyzed roll-call data from the 16th, 17th, and 18th National Assemblies and found that the state of polarization in Korean party politics is severe and has become remarkably worse since the 17 th National Assembly. Kang (2012) examined roll-call data and found that political polarization was particularly prominent in foreign policy discussions during the 19th National Assembly. Lee (2015) concurred, suggesting that political polarization in South Korean politics has accelerated since the 2000s not just as a result of debates over domestic issue such as expanding universal welfare but foreign policy and trade issues such as Korea's involvement in the Iraq War, the prospects of a Korea-US free trade agreement, and importing American beef.

Such polarization likely peaked in 2016-17 (Jung 2018). In December 2016, the National Assembly impeached President Park Geun-hye, a member of the conservative party. She was later removed from office by a unanimous decision of the Constitutional Court in March 2017 (Shin and Moon 2017). The polarized post-impeachment atmosphere is reflected in the 20th National Assembly's bill passage rate-approximately 36 percent, the lowest in the National Assembly's history. ${ }^{1}$ Furthermore, this period saw an increase in conservative politicians' extra-parliamentary political activity, insofar as the liberal, public-led candlelight rallies were met by conservative, civil society-led Taegeukgi rallies involving conservative politicians (Cho and Lee 2021; Hwang and Willis 2020; Min and Yun 2018; Oh 2019; Reijven et al. 2020). These may partially explain the phenomenon of political polarization, but the bill passage rate and Taegeukgi rallies do not empirically prove that political polarization in South Korean has intensified since President Park's impeachment.

The studies aiming to prove political polarization are either based on roll-call data or survey data. Roll-call data are relatively easy to access, can be easily modified and applied, and can function as data in themselves. This makes it easy to apply them as a way to measure political polarization. Hence, many studies have used roll-call data to study polarization and ideology (e.g., Poole and Rosenthal 1997; Ansolabehere, Snyder, and Stewart 2001; Jeon 2006; Poole 2007; Garand 2010; Abramowitz 2010; Shor and McCarty 2011; Lee and Lee 2015; Lee 2015). However, some studies have argued that this approach does not travel well in the parliamentary context (Schwarz, Traber, and Benoit 2017) because the voting data captured in roll-call data may reflect selection bias for politicians' votes (Carrubba et al. 2006; Carrubba, Gabel, and Hug 2008; Hug 2010). Politicians' votes may not directly reflect 
their ideological positions-they may reflect the influence of other factors, such as politicians' personal interests and their relations with the ruling government (Sinclair 1982, 2000; Benedetto and Hix 2007; Kam 2009). This approach also overlooks the context of the legislative process, which is key to understand ideology (Jessee and Theriault 2014). For example, by focusing on votes, these studies cannot account for deliberation which arrives at consensus or the fact that some politicians abstain from voting or are not present at the vote. Such studies would mischaracterize voting results' relationship to ideology, perhaps especially in highly polarized contexts such as the Korean National Assembly.

Furthermore, decision-making processes at the party level can affect the individual lawmakers' votes regardless of their personal ideological dispositions. For example, as a party becomes more conservative, its members are likely to vote more conservatively regardless of their own stances on a given issue. This is especially true in South Korea, where party leadership has a strong influence over individual lawmakers (Jeon 2014; Lee and Lee 2011). In this case, the lawmaker is given a more conservative NOMINATE score than his or her ideological orientation. In other words, increases in the ideological distance between lawmakers and their political party's leadership might predict their overall ideological polarization. In NOMINATE-based analysis, it is necessary to decide which legislation and lawmakers to include in the analysis target, but there is no statistical or theoretically established criterion for this yet in literature.

Other studies (e.g. Lee 2011; Kang 2012; Ka 2014, 2016, Park et al. 2016; Park et al. 2016 Jung 2018) have used National Assembly survey data to study polarization in South Korean politics. Like the roll-call data, these data are also widely availablemembers of the National Assembly have filled out questionnaires on their ideological orientation since 2002. However, this method also has limitations. First, lawmakers sometimes refuse to respond to these surveys. For example, only 56.91 percent members from the Democratic Party, 55.7 percent from the Saenuri Party, 42.11 percent from the People's Party, and 16.67 percent from the Justice Party responded to a survey of the 20th National Assembly (Park et al. 2016, 127). Second, if the questionnaire items do not remain consistent over time, it might be more difficult to reliably measure lawmaker' ideology over time. Finally, and above all, this method relies on lawmakers' self-reported responses, so it is difficult to regard them as objective data-not the least because these responses do not reflect politicians' actual actions and may be strategically adjusted for the context of a study.

Other studies have undertaken qualitative analyses of National Assembly subcommittee meeting minutes. Kwon and Lee (2012) classified lawmakers' remarks in the minutes of the standing committee of the 17th National Assembly into those that reflected partisanship, representativeness, professionalism, and compromise. Their analysis showed that partisan criticisms and personal attacks were less prominent in these minutes than the other three types; instead, they found that the minutes reflected a search for opinions based on expert knowledge and the identification of causal relationships. Ka et al. (2008) analyzed the same meeting minutes in order to study National Assembly members' participation in the meeting and the subcommittee's decision-making processes. They found that the standing committee's decision-making method was closer to a consensus system than a majority system by showing that proposals for the chairman's resolutions were more common than 
votes. However, these qualitative analyses have two problems. First, the researchers' subjective selection of data makes it difficult for other researchers to reproduce their results. Second, it is difficult to extract sufficiently meaningful information from this kind of data, especially given the large (and increasing) volume of meeting minute data. Below, in the methodology section, this study discusses why current study chose to use an NLP model to overcome the limitations with previous studies described above and describe the use of the model.

\section{Methodology}

\section{NLP techniques}

Unlike the roll-call-based approach, an NLP approach to meeting minutes analyzes the discussion process rather than voting results. Unlike the survey-based approach, an NLP approach analyzes the degree to which politicians' political polarization reflects their actual actions (in this case, behavior in subcommittee meetings). This approach can analyze vast amounts of meeting minutes using algorithms, which can be used by other researchers, making the results highly reproducible (see Appendix A for more details about NLP and see Appendix B for NLP code).

Other studies in political science and the social sciences have used NLP techniques to measure political polarization. These studies value these techniques because they allow the use of large amounts of text data using supervised or unsupervised learning approaches (Haselmayer and Jenny 2017; Wilkerson and Casas 2017; Goet 2019; Pozen, Talley, and Nyarko 2019; Gentzkow, Shapiro, and Taddy 2019; Proksch et al. 2019; Chang and Masterson 2019; Hausladen, Schubert, and Ash 2020). This study trains a model to learn political language from meeting minutes (see below) and then classifies text data to quantify political polarization.

If political parties maintain disparate positions as a result of their ideological characteristics and these parties' members use language accordingly, NLP model should be able to classify text by learning the respective languages of liberal and conservative parties and then identifying classification elements. Figure 1 summarizes the data analysis process: the current study built NLP model using 20 years' worth of subcommittee text data, excluding that of the Legislation and Judiciary Committee, and then classified the text from the second subcommittee of the Legislation and Judiciary Committee as the target text.

The logic of text classification is as follows. Text classification refers to the process of receiving a sentence (or word) as input and classifying where the sentence belongs between pre-trained (defined) classes. That is, in advance, by classifying the sentences or words to be learned into binary (conservative vs liberal), the NLP model learns through the learning process (training process), and the target text is input and classified. To explain it based on Figure 1, the learning process means the process of learning to which class the sentences (or words) related to a specific issue belong through the "Training, tuning, and evaluation" (corresponding to "NLP model learning code" in Appendix B). And by classifying "Target Data" through the trained model, we can estimate the polarization (corresponding to "Test code" in Appendix B).

The logic of quantification of polarization is as follows. If the classification model can accurately distinguish between the language of given political parties, it will be 


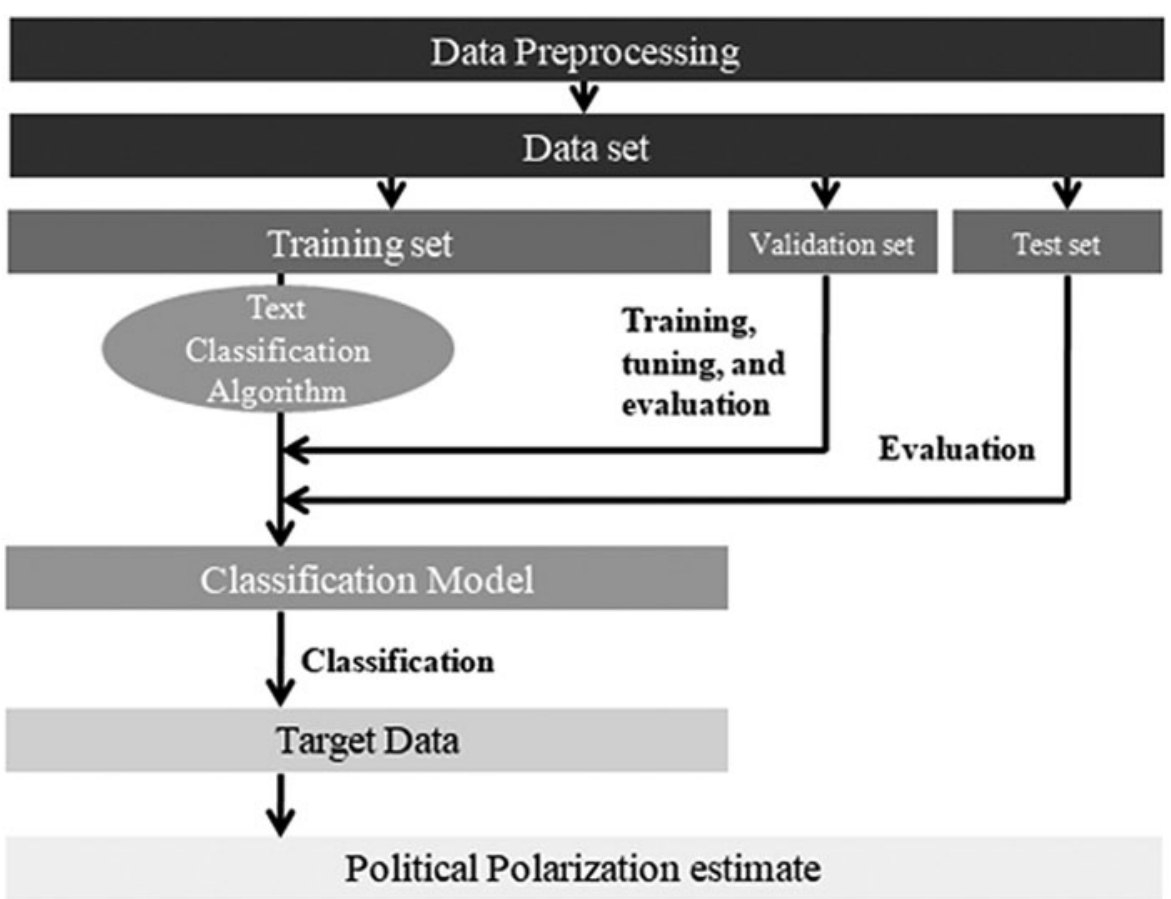

Figure 1. Political polarization estimate process using NLP

considered to indicate significant ideological polarization between those factions. If the trained model cannot do so, then the degree of polarization between these parties' ideological positions will be considered to be small or insignificant. The classification model that learned the language of each party for 20 years classifies each meeting minute of the second subcommittee of the Legislation and Judiciary Committee. We can convert the accuracy (degree of polarization) of each into time-series data.

This study uses bidirectional encoder representations from transformers (BERT), a neural networks model that dynamically generates word vectors utilizing contexts and learning them in both directions according to context (see Appendix A for more details). BERT is a semi-supervised learning model that builds a general-purpose language understanding model using unsupervised learning of a large corpus. It fine-tunes this model using supervised learning and applies it to other work (Devlin et al., 2019). Simply put, BERT uses pre-learning within a text corpus to create a model that understands the basic patterns of language, and transfer learning is then performed by applying this model to new tasks. In this way, BERT combines the advantages of unsupervised and supervised learning approaches. Unsupervised methods come with significant post hoc validation costs, as the researcher "must combine experimental, substantive, and statistical evidence to demonstrate that the measures areas conceptually valid as measures from an equivalent supervised model" (Grimmer and Stewart 2013, 271). However, as described above, BERT performs a classification task through supervised learning 
by transferring a model learned through unsupervised learning. Therefore, current study compared the results of Generative Pre-trained Transformer 2 (GPT-2) (Ethayarajh 2019), another transformer-based learning model, to validate the results.

This study utilized Google Colab Python 3 and Pytorch as analytic tools. This study also applied BERT with the Hugging Face transformer model installed. Hugging Face is a useful Pytorch interface designed for utilization with BERT. The library includes pre-build modifications of the model, which enables specific tasks, such as classification. When fine-tuning BERT model, this study established the following: batch size of 32, learning rate (Adam) of 2e-5, and 3 epochs. In dividing the data into training, validation, and testing data in the model-building process, this study first set 30 percent of the total data as test data and then 10 percent of the training data as validation data (see Appendix B for seeing the process of building BERT NLP model, additionally GPT-2 NLP model).

\section{Data}

Data that best reflect the functions of politicians' political language are necessary to measure political polarization. This study proposes an approach in which the model learns the entire minutes of the Standing Committee subcommittees except for the Legislation and Judiciary subcommittee and then classifies the minutes of the second subcommittee of the Legislation and Judiciary Committee.

Figure 2 shows the South Korean legislative process. The subcommittee is responsible for practical legislation and government budget review within National Assembly committees. Standing committees in different fields, including education, diplomacy, national defense, labor, and the environment, include three to six subcommittees each with narrower roles. If a bill's contents are simple or uncontentious, it is not referred to subcommittees. If they are, the relevant committee refers the bill to a subcommittee for review after a general discussion. The final resolutions of bills are done in plenary sessions of the National Assembly after they have been reviewed by each standing committee. It is common for bills to be passed during plenary sessions without discussion. Not all bills and budgets are reviewed by the standing committee; in such cases, subcommittees conduct a practical review of the given bills.

All bills passed by each standing committee are examined by the second subcommittee of the Legislation and Judiciary Committee (see Figure 2). This subcommittee performs the final review before a bill is transferred to the plenary session; it thus effectively serves a role similar to that of the United States Senate. The second subcommittee reviews whether the bill conflicts with existing bills or violates the constitution and refines the wording of bills. It is during this process that each party's positions on the bill become clear. Thus, political language is actively used in the standing committee subcommittees and in the second subcommittee of the Legislation and Judiciary Committee in particular.

Article 50, Clause 1 of the South Korean Constitution states that the National Assembly must disclose the bill review process to the public, with the exception of bills that concern national security (Article 50, Clause 1 of the Constitution; Article 75 of the National Assembly Act) and meetings of the intelligence committee (Article 54-2 of the National Assembly Act). Thus, sample data are quite 


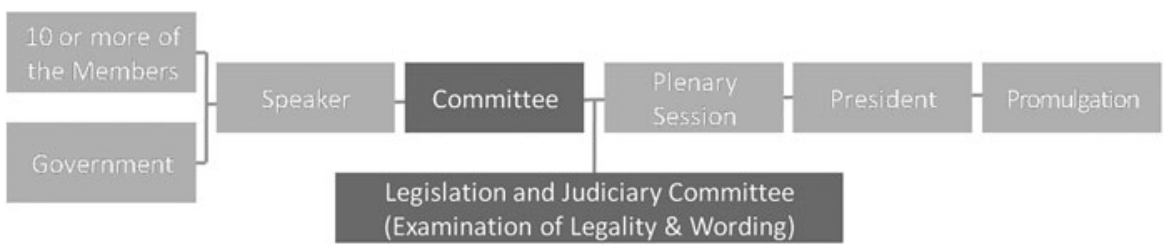

Figure 2. The process of enacting and amending a law in South Korea Data from: The National Assembly of the Republic of Korea (https://korea.assembly.go.kr:447/int/act_01.jsp).

comprehensive, not limited to certain subcommittees. They contain meeting minutes from all standing committee subcommittee meetings between July 2000 and May 2020. Current research gave the Democratic Party of Korea (the leading liberal party) a value of zero and the People's Power Party (the leading conservative party) a value of one when pre-processing the minute data for training. These two leading parties have won most of the seats in South Korean parliament since the 1990s; this study refers to them by their current names (as of 2021) for convenience. This study also classified data which represent the actions of lawmakers from minor parties within the National Assembly in a binary manner, accounting for their political inclination to form coalitions with either of the two major parties. This study acknowledges that the classification of minor parties cannot but be subjective (see Appendix C for more details).

When pre-processing the subcommittee data, this study noted that documents from the 16th and 17th National Assemblies presented the names of assembly members in Chinese characters instead of Korean letters. Thus, this study had to translate their names into Korean. This study excluded unnecessary or irrelevant information, such as descriptions of the documents and remarks by other persons, from the analysis. It is important to pre-process the data so that we can better analyze relevant dialog and exchanges among relevant parties.

\section{Results}

Figure 3 shows the results of BERT model of 17 years' worth of subcommittee meeting data. For comparison, the red line marking a value of 0.7 is the benchmark for a high degree of polarization, and the blue dotted line marking a value of 0.5 is the average accuracy result of evaluating the test data in the process of building the BERT classification model. The green dotted line represents the degree of polarization, and the orange line represents the trend. The X-axis marks the years 2004-2020 (from the 17th to the 20th National Assembly) and the administration in each period.

Figure 3 shows that there is a trend toward increasing political polarization. Although polarization remained relatively steady between 2004 and the early 2010 s and even decreased between 2011 and 2014, it rebounded during the first half of 2014 and has risen sharply and remained high since late 2016. Figure 4 displays changes in political polarization between 2004 and 2020, by National Assembly.

The figure indicates that the average degree of polarization was similar in the 17th (0.4953) and 18th (0.485) National Assemblies. Polarization waxed and waned during the 17th National Assembly, rose sharply in April 2010, and then trended downward 


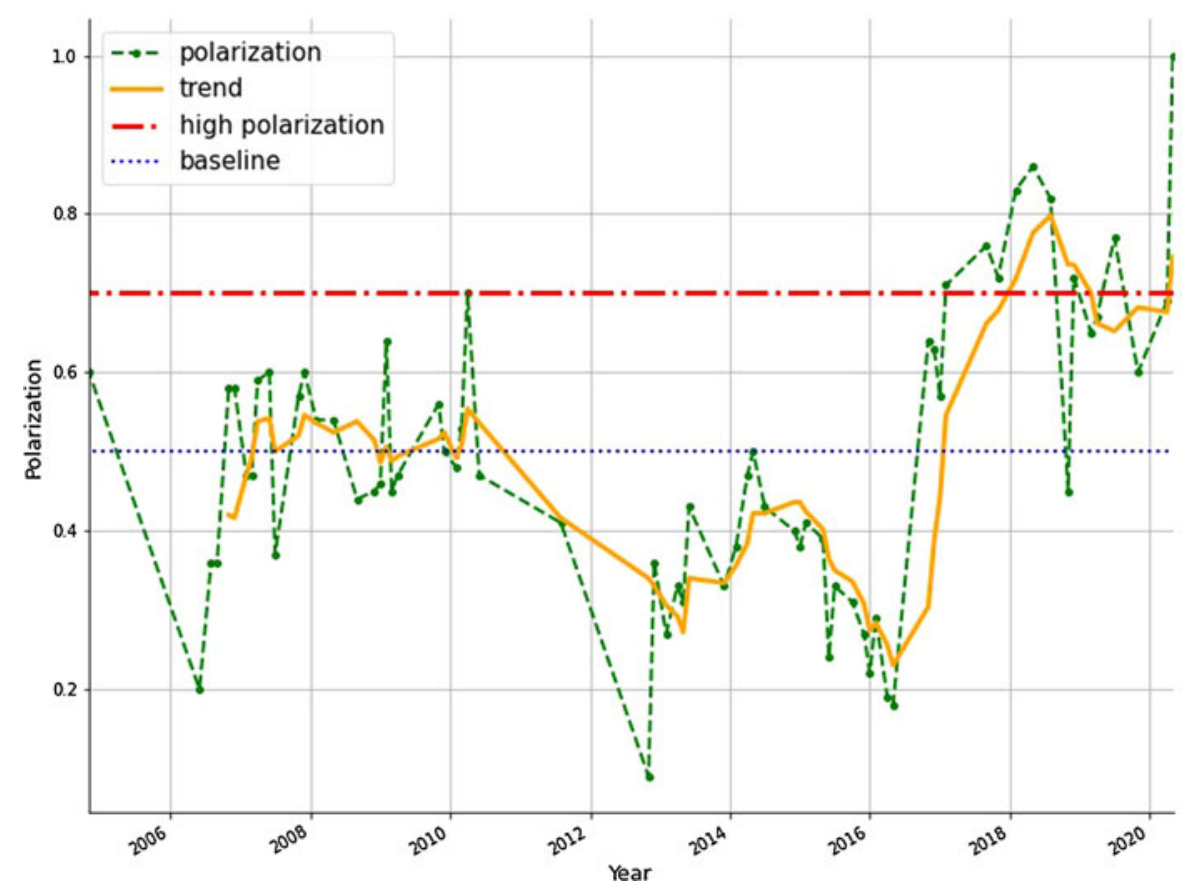

Figure 3. Political polarization, 2004-2020

for the rest of the 18th National Assembly. The average degree of polarization during the 19th National Assembly was 0.3265; it rose during April and May 2014 and then began to decline. Polarization was most severe during the 20th National Assembly, in which the average degree of polarization was 0.7043 . The data indicate that polarization rapidly escalated in February and March 2009, April 2010, June 2013, May 2014, and November 2016. Although it usually decreased after these escalations, polarization has remained very high since 2016-17. From a data-intuitive perspective, it may rise and fall due to noise in the data. However, remaining high should be interpreted in a different context. This finding implies that polarization is becoming and remaining more intense over time rather than returning to normal or exhibiting the wax/ wane pattern of previous National Assemblies. Given that this model captures wider political differences beyond particular legislation, this study interprets pre-2016 cycles in polarization as reflecting regular politics and debate and the high level of post-2016 polarization as capturing a growing and more enduring set of ideological differences between ruling and opposition parties. Figure 5 compares the results of the BERT and GPT- 2 models. They exhibit similar trends in polarization, especially after 2016, thus validating the findings.

\section{Discussion}

The above section described the process and the finding that increasingly polarized political language indicates a serious, more enduring, and deepening polarization 
(a) 17th National Assembly (2004-2008)

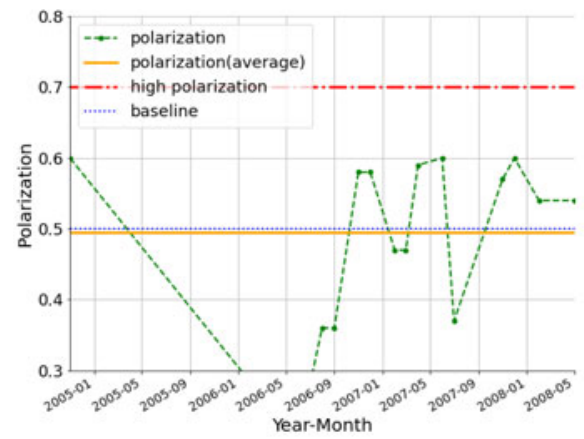

(c) 19th National Assembly (2012-2016)

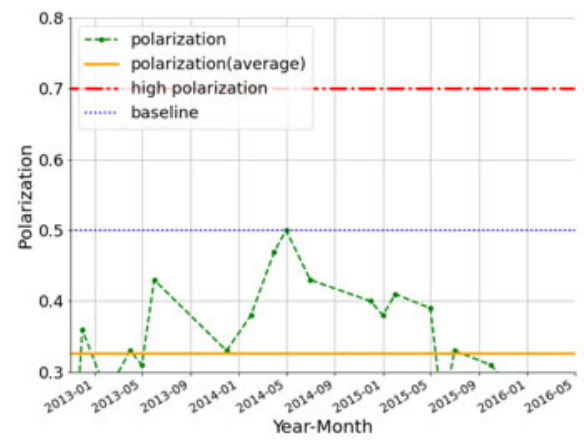

(b) 18th National Assembly (2008-2012)

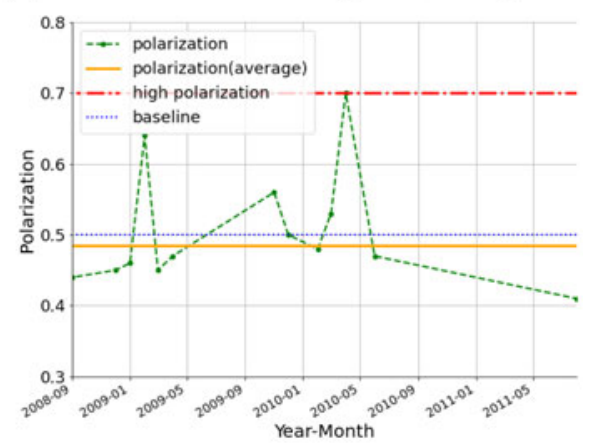

(d) 20th National Assembly (2016-2020)

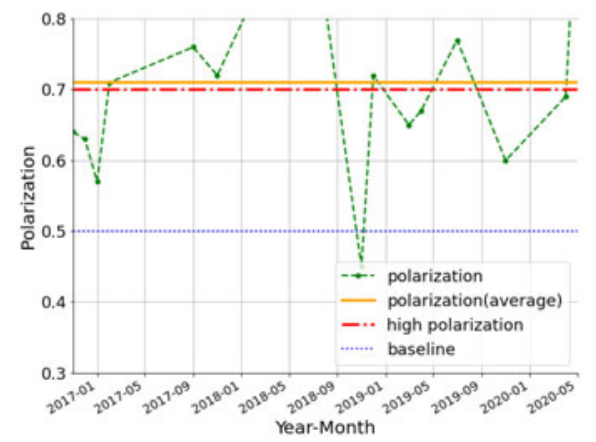

Figure 4. Political polarization, 2004-2020, by National Assembly

between political elites in South Korea. This deepening tension leads each of the parties to use different political language and stoke division on particular issues. This study also found that the more polarizing the language used in meeting minutes, the more polarized politics becomes (e.g. the growth in partisan language after 2016). These conflicts have obvious consequences for the legislative process.

There may be several reasons behind the increase in polarization post-2016, but the impeachment of President Park undeniably looms largest among them. After Moon Jae-in was elected following the impeachment, his administration promoted investigations which framed the previous two conservative administrations (Park Geun-hye administration and Lee Myung-bak administration) as corrupt and untrustworthy (B. Kim 2019; Kirk 2020; Lee 2018). These included the creation of a special committee to confiscate the illegitimate proceeds earned by former president Park Geun-hye and her longtime friend Choi Soon-sil. The Moon Jae-in administration's core and public focus on correcting the mistakes and injustices of previous governments formed by the opposition party has had a lingering and polarizing effect on Korean political discourse. Although these policies nominally aimed to restore and improve South Korean democracy, they have instead made Korean politics so polarized that party politics is nearly impossible. There have been no joint efforts between 


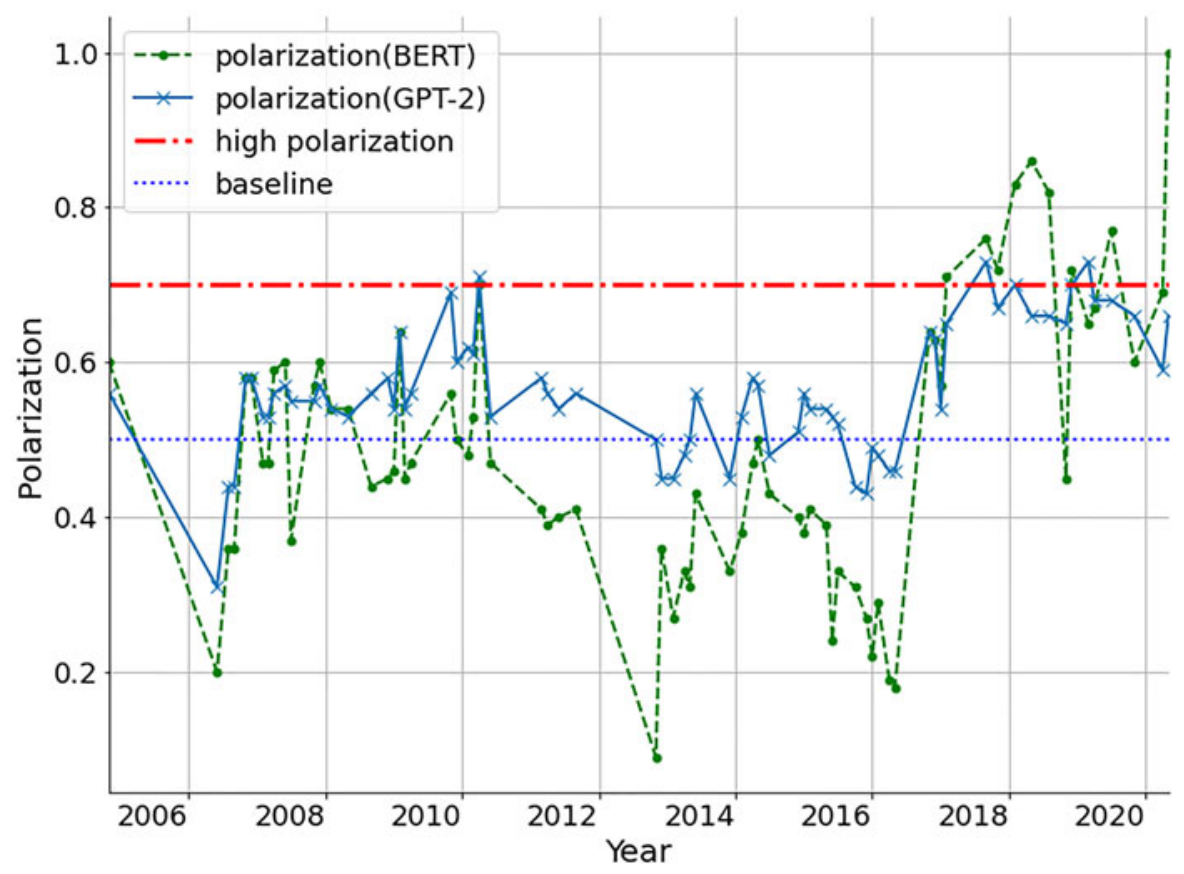

Figure 5. Comparing the BERT and GPT-2 models

the two parties to create an inclusive, good-faith, post-impeachment regime in the public interest, and this has led to a culture of slander and personal attacks.

Unfortunately, the politicians who made up a large part of the conservative party opposed or denied the impeachment, and ironically disparaged and rejected the democratically constituted Moon Jae-in administration (Kim 2020). On the other hand, the faction leading the impeachment regarded the opposition faction only as an object of reform and did not accept it as an object of cooperation, driving parliamentary politics into a hostile confrontation. Following the impeachment, Park's partythe People's Power Party-conducted political activities outside of parliament, such as the Taegeukgi street rallies (Cho and Lee 2021; T.-H. Kim 2019). These rallies turned violent and, in turn, damaged the legislative process and the prospect for effective parliamentary politics (Cho and Lee 2021; Kwon 2020). Conflicts between two factions persisted throughout the 20th National Assembly, and the findings of this study can be interpreted as reflecting the language of conflict in the process of legislation (in terms of bill passage rate, the passage rate of bills proposed by lawmakers was particularly low in the 20th National Assembly. see Appendix D for details).

\section{Conclusions}

This study's findings indicate that political polarization has waxed and waned in South Korea's National Assembly since 2004, but increased sharply in late 2016 and has remained at a high level since. This indicates that South Korea, similar to many 
other countries, is affected by the widening and deepening phenomenon of political polarization. I conclude this study by discussing some implications of the findings.

The findings have important implications for the National Assembly moving forward. The analysis indicates that persistent use of polarizing political language stokes polarization in general. This is likely because it removes opportunities for politicians to find (or seek) common ground from which to build a compromise. These findings imply that bills whose contents are closely related to people's everyday lives and give the parties their few opportunities to make ideological gains may not be properly reviewed, and that those which have a lot of ideological content often face dead lock and/or last-resort negotiations. These findings also imply that polarization can undermine other important functions of the National Assembly, such as conducting confirmation hearings. Furthermore, an increasingly polarized environment pushes political parties to seek ideological gains rather than governance-they support or maintain policies which only appeal to their supporters, cast all political issues as dichotomous, and perpetuate a picture of their political opponents as enemies rather than parliamentary colleagues. Members of the 21st National Assembly, which opened in June 2020, should seek to avoid increasingly polarizing language and aim to resolve polarization and create cross-party dialog.

The current study has some shortcomings, but it contributes to the development of the analysis of political polarization based on NLP, analyzes the polarization of South Korean politics, complements previous studies with the new approach and gathers data that can be of use for further studies. Above all, this study opens up new areas of analysis of political phenomena using neural network algorithms.

The limitations of this study and suggestions for follow-up studies are as follows. First, this study's proposed causal link between language and political polarization is tentative and begs further exploration. This study's empirical findings are only suggestive; although it helps us understand the trends and timing of the escalation of polarization in South Korean politics since 2004, it does not suggest causes for this phenomenon or specify which social issues exacerbated polarization. Furthermore, it is difficult to determine clearly whether the polarization of political language is influenced by a particular political phase, represents a position on a particular bill, or is caused by an interaction between the two.

When measuring polarization in elite politics, there is no data directly representing polarization in the real world. Therefore, this study utilized the tool of the language of the space of the National Assembly, which is considered to reflect the political polarization. In terms of language as a proxy variable, the possibility of a certain level of error in its measurement is open. In a follow-up study, it is necessary to compare it with the result of analyzing the roll-call data of the 20th National Assembly in order to analyze the political polarization in more depth.

Second, polarization has multiple meanings - it can refer to gaps between parties' ideological tendencies or their to polarizing behavior (e.g., basing political positions on factional logic and the need to score ideological wins rather than focusing on governance). While both beget confrontation and conflict, the former presupposes a polarization of opinion and the latter does not. This study's approach makes it difficult to clearly determine whether the conflict between liberals and conservatives in 
South Korea is attributable to differences in their ideological orientation or politicians voting by party lines or logic.

Third, as mentioned above, previous studies have found that polarization is more prominent in certain fields, such as foreign policy (Kang 2012; Park et al. 2016). However, this study cannot contribute to this argument because this study analyzed meeting minutes in general without specifying a field of focus. Although polarization is a broad phenomenon with many disparate effects, it is important for future researchers to determine which dimensions of politics are most polarized or polarizing so that we can better understand and overcome polarization.

Fourth and finally, the polarization of South Korean parliamentary politics reported in this study does not necessarily reflect the overall polarization of South Korean society or political discourse. Political elites may be polarized without the masses being similarly polarized. Future studies should analyze the polarization of the masses in more detail.

Acknowledgement. I thank the anonymous reviewers and the editor for their thoughtful reviews and helpful comments on the previous drafts. Their comments greatly contributed to the improvement of the quality of this manuscript.

Conflict of Interest. The author declares none.

Funding. The author received no financial support for the research, authorship, and/or publication of this article.

\section{Note}

1. Bill Information (https:/likms.assembly.go.kr/bill/stat/statFinishBillSearch.do).

\section{References}

Abramowitz, Alan I. 2010. The Disappearing Center. New Haven: Yale University.

Abramowitz, Alan I., and Kyle L. Saunders. 2008. “Is Polarization a Myth?” The Journal of Politics 70 (2): 542-555.

Ansolabehere, Stephen, James Snyder, and Charles Stewart. 2001. "The Effects of Party and Preferences on Congressional Roll-Call Voting." Legislative Studies Quarterly 26 (4): 533-572.

Baldassarri, Delia, and Andrew Gelman. 2008. "Partisans without Constraint: Political Polarization and Trends in American Public Opinion." American Journal of Sociology 114 (2): 408-446.

Banda, Kevin K., and John Cluverius. 2018. "Elite Polarization, Party Extremity, and Affective Polarization." Electoral Studies 56: 90-101.

Benedetto, Giacomo, and Simon Hix. 2007. "The Rejected, the Ejected, and the Dejected: Explaining Government Rebels in the 2001-2005 British of Commons." Comparative Political Studies 40 (7): 755-781.

Binder, Sarah A. 1999. The Dynamics of Legislative Gridlock, 1947-96. The American Political Science Review 93 (3): 519-533.

Brady, David, and Craig Volden. 1998. Revolving Gridlock. Boulder: Westview.

Carrubba, Clifford J., Matthew Gabel, and Simon Hug. 2008. "Legislative Voting Behavior, Seen and Unseen: A Theory of Roll-Call Vote Selection." Legislative Studies Quarterly 33 (44): 543-572.

Carrubba, Clifford J., Matthew Gabel, Lacey Murrah, and Ryan Clough. 2006. "Off the Record: Unrecorded Legislative Votes, Selection Bias and Roll-Call Vote Analysis.” British Journal of Political Science 36 (4):691-704. 
Chang, Charles, and Michael Masterson. 2019. "Using Word Order in Political Text Classification with Long Short-term Memory Models." Political Analysis 28 (3): 395-411.

Cho, Kisuk. 1998. "Regionalism in Korean Elections and Democratization: An Empirical Analysis." Asian Perspective 22 (1): 135-156.

Cho, Sarah, and Juheon Lee. 2021. "Waving Israeli Flags at Right-Wing Christian Rallies in South Korea." Journal of Contemporary Asia 51 (3): 496-515.

Devlin, Jacob, Ming-Wei Chang, Kenton Lee, and Kristina Toutanova. 2019. "BERT: Pre-training of Deep Bidirectional Transformers for Language Understanding." Proceedings of the NAACL-HLT 2019, June 2-7, 2019, Minneapolis, Minnesota.

Druckman, James N., Erick Peterson, and Rune Slothuus. 2013. "How Elite Partisan Polarization Affects Public Opinion Formation." American Political Science Review 107 (1): 57-79.

Edelman, Murray. 1985. "Political Language and Political Reality." PS: Political Science \& Politics 18 (1): $10-19$.

Ethayarajh, Kawin. 2019. "How Contextual are Contextualized Word Representations? Comparing the Geometry of BERT, ELMo, and GPT-2.” arXiv: 1909.00512.

Fleisher, Richard, and John R. Bond. 2004. "The Shrinking Middle in the US Congress." The British Journal of Political Science 34 (3): 429-451.

Garand, James C. 2010. "Income Inequality, Party Polarization, and Roll-Call Voting in the U.S. Senate." The Journal of Politics 72 (04):1109-1128.

Gentzkow, Matthew, Jesse M. Shapiro, and Matt Taddy. 2019. "Measuring Group Differences in High-dimensional Choices: Method and Application to Congressional Speech." Econometrica 87 (4): $1307-1340$.

Gilmour, John B. 1995. Strategic Disagreement: Stalemate in American Politics. Pittsburgh: University of Pittsburgh Press.

Goet, Niels D. 2019. "Measuring Polarization with Text Analysis: Evidence from the UK House of Commons, 1811-2015." Political Analysis 27: 518-539.

Goldberg, Yoav. 2017. "Neural Network Methods in Natural Language Processing." Synthesis Lectures on Human Language Technologies 10 (1): 1-309.

Grimmer, Justin, and Brandon M. Stewart. 2013. "Text as Data: The Promise and Pitfalls of Automatic Content Analysis Methods for Political Texts." Political Analysis 21 (3): 267-297.

Groseclose, Tim, and Nolan McCarty. 2001. "The Politics of Blame: Bargaining Before an Audience." American Journal of Political Science 45 (1): 100-119.

Han, JeongHun. 2021. "How Does Party Organization Develop Beyond Clientelism in New Democracies? Evidence from South Korea, 1992-2016." Contemporary Politics 27 (2): 225-245.

Harris, Zellig S. 1954. "Distributional Structure." WORD 10 (23): 146-162.

Haselmayer, Martin, and Marcelo Jenny. 2017. "Sentiment Analysis of Political Communication: Combining a Dictionary Approach with Crowd Coding." Quality \& Quantity 51: 2623-2646.

Hausladen, Carina., Marcel H. Schubert, and Elliott Ash. 2020. "Text Classification of Ideological Direction in Judicial Opinions," International Review of Law and Economics 62: 105903.

Hetherington, Marc J. 2005. Why Trust Matters: Declining Political Trust and the Demise of American Liberalism. Princeton: Princeton University Press.

Hibbing, John R., and Elizabeth Theiss-Morse. 1995. Congress as Public Enemy: Public Attitudes Toward American Political Institutions. New York: Cambridge University Press.

—. 2002. Stealth Democracy: Americans' Beliefs about How Government Should Work. New York: Cambridge University Press.

Hix, Simon, and Hae-Won Jun. 2009. "Party Behavior in the Parliamentary Arena: The Case of the Korean National Assembly.” Party Politic 15 (6): 667-694.

Horiuchi, Yusaku, and Seungjoo Lee. 2008. "The Presidency, Regionalism, and Distributive Politics in South Korea." Comparative Political Studies 41 (6): 861-882.

Hug, Simon. 2010. "Selection Effects in Roll Call Votes." British Journal of Political Science 40 (1): 225-235.

Hwang, Injeong, and Charmaine N. Willis. 2020. "Protest by Candlelight: A Comparative Analysis of Candlelight Vigils in South Korea." Journal of Civil Society 16 (3): 260-272.

Jeon, Jin-Young (전진영). 2006. "국회의원의 갈등적 투표행태 분석: 제 16 대 국회 전자표결을 중심으로” [A Study of Members' Conflictual Voting Behavior in the 16th Korean National Assembly]. 한국정치학회보 [Korean Political Science Review] 40 (1): 47-70. 
2014. “국회 원내지도부의 입법영향력 분석: 상임위원회 지도부를 중심으로” [The Keys to Legislative Success in the National Assembly of Korea: The Role of Committee Leadership]. 한국정당학회보 [The Korean Association of Party Studies] 13 (2): 193-21.

Jessee, Stephen A., and Sean M. Theriault. 2014. "The Two Faces of Congressional Roll-Call Voting." Party Politics 20 (6): 836-848.

Jung, Dong-Joon (정동준). 2018. “2018년 지방선거 이후 유권자들의 정치 양극화” [Political Polarization among South Korean Citizens after the 2018 Local Elections-The Rise of Partisan Sorting and Negative Partisanship]. OUGHPOPIA 33 (3): 143-180.

$\mathrm{Ka}$, Sang Joon (가상준). 2014. “한국 국회는 양극화되고 있는가?” [Has the Korean National Assembly been polarized?] 의정논총 [Journal of Parliamentary Research] 9 (2): 247-272

—. 2016. 정책영역별로 본 국회 양극화 [Policy Attitude of Legislators and Polarization of the National Assembly]. OUGHTOPIA 31 (1): 327-354.

$\mathrm{Ka}$, Sang Joon (가상준), Jin Man Cho, Jun Young Choi, and Byoung Kwon Sohn (가상준 조진만 최진영 손병권). 2008. “회의록 분석을 통해서 본 국회 상임위원회 운영의 특징” [Characteristics of Standing Committees' Operation in the National Assembly with an Analysis of Assembly Records]. 21세기정치학회 [21 ${ }^{\text {st }}$ century Political Science Review] 18(1): 47-68.

Kam, Christopher J. 2009. Party Discipline and Parliamentary Politics. Cambridge: Cambridge University Press.

Kang, Won Taek (강원택). 2012. “제19대 국회의원의 이념 성향과 정택 태도” [Ideological Positions and Policy Attitudes of the $19^{\text {th }}$ National Assembly of Korea]. 의정연구 [Korea Legislative studies Institute] 36 (2): 5-38.

- 2018. “한국 정당 정치 70년: 한국 민주주의 발전과 정당 정치의 전개” [Development of Party Politics in South Korea from 1948 to 2018: Five Historic Moments]. 한국정당학회보 [Korean Party Studies Review] 17 (2): 5-31.

Kang, Woo Chang. 2016. "Local Economic Voting and Residence-based Regionalism in South Korea: Evidence from the 2007 Presidential Election." Journal of East Asian Studies 16 (3): 349-369.

Kim, Brian. 2019. "GSOMIA and the Shadow of 'Lee-Myung-Park-Geun-Hye': A Tale of Political Revenge?" The Diplomat, September 10, https://thediplomat.com/2019/09/gsomia-and-the-shadow-oflee-myung-park-geun-hye/ (accessed May 20, 2021).

$\mathrm{Kim}$, Jongcheol (김종철). 2020. “제 20 대 국회 평가와 제 21 대 국회의 나아갈 방향: 의회주의의 관점에서" [What Lessons Can be Taken from the 20th National Assembly?] 입 법학연구 [Journal of Legislation Studies] 17 (2): 5-45.

Kim, Tong-Hyung. 2019. "S. Korean Opposition Leader Shaves Head to Protest Minister." NP NEWS, September 16, https://apnews.com/article/09a3a1964bca444e8f75bea521e1738a (accessed April 20, 2021).

Kim, Youngmi. 2008. "Intra-Party Politics and Minority Coalition Government in South Korea." Japanese Journal of Political Science 9 (3): 367-389.

Kirk, Donald. 2020. "Korea’s Ex-President Lee, One-Time Hyundai Chaiman, Back In Jail In Scandal Involving Samsung." Forbes, February 20, www.forbes.com/sites/donaldkirk/2020/02/20/koreas-ex-president-lee-onetime-hyundai-chairman-back-in-jail-in-scandal-involving-samsung/?sh=6e0ca2891d19 (accessed March 20, 2021).

Krehbiel, Keith. 1998. Pivotal Politics: A Theory of U.S. Lawmaking. Chicago: University of Chicago Press. Kwak, Jin-Young (곽진영). 1998. “정당체제의 사회적 반영의 유형과 그 변화” [The Patterns of Social Reflection of Party Systems and Their Changes: A Comparative Analysis of Korea, Japan and the USA]. 한국정치학회보 [Korean Political Science Review] 32 (1): 175-202.

Kwon, Eun Sil, and Young Hwan Lee. 2012. "A Study on Decision Determinants in the National Assembly." Korean Society and Public Administration 23 (1): 317-341.

Kwon, Jake, and Julia Hollingsworth. 2020. "Former South Korean Prime Minister Among 29 Politicians Charged Over Mass Brawl.” CNN, January 3, www.cnn.com/2020/01/03/asia/south-korea-lawmakersindicted-intl-hnk/index.html (accessed May 20, 2021).

Kwon, Keedon. 2004. "Regionalism in South Korea: Its Origin and Role in Her Democratization." Politics e Society 32 (4): 545-574.

Layman, Geoffrey C., and Thomas M. Carsey. 2000. "Ideological Realignment in Contemporary American Politics: The Case of Party Activists." Annual Meeting of the Midwest Political Science Association, April 27-30, 2000. Chicago, Illinois. 
2002. "Party Polarization and "Conflict Extension" in the American Electorate." American Journal of Political Science 46 (4): 786-802.

Lee, Hyun-Chool, and Alexandre Repkine. 2020. "Changes in and Continuity of Regionalism in South Korea: A Spatial Analysis of the 2017 Presidential Election." Asian Survey 60 (3): 417-440.

Lee, Joyce. 2018. "South Korean Court Raises Ex-President Park's Jail Term to 25 years." Reuters, August 23, www.reuters.com/article/us-southkorea-politics-park-idUSKCN1L905P (accessed May 19, 2021).

Lee, Kap-Yun, and Hyeon-Woo Lee (이갑윤 이현우). 2008. “이념투표의 영향력 분석: 이념의 구성, 측정 그리고 의미” [A Study of Influence of Ideological Voting: Scope, Measurement and Meaning of Ideology]. 현 대정치연구 [Journal of Contemporary Politics] 1 (1): 137-166.

Lee, Kap-Yun, and Hyeon-Woo Lee (이갑윤 이현우). 2011. "국회의원 표결과 정당 영향력: 17대 국회를 대상으로" [Partisan Influence on Congressional Voting: In Cases of the 17th Korean National Assembly]. 한국정치연구 [Journal of Korean Politics] 20 (2): 1-27.

Lee, Nae Young. 2011. "Main Source of Ideological Conflict in Korea: Public Polarization or Elite Polarization?" Korean Party Studies Review 10 (2): 251-287.

— 2015. "Politics of Party Polarization and Democracy in South Korea." ASIAN Barometer Working Paper Series 103.

Lee, Nae Young, and Hojun Lee. 2015. "Party Polarization in the South Korea National Assembly: An Analysis of Roll-Call Votes in the 16-18th National Assembly." Journal of Parliamentary Research 10 (2): $25-54$.

Lim, Heui Seok (임희석). 2019. 자연어처리 바이블 [Natural Language Processing Bible]. Seoul: Human Science.

Lim, Wonhyuk, Changkeun Lee, Seeun Jung, and Dongook Choi. 2019. Opinion Polarization in Korea: Its Characteristics and Drivers, KDI Research Monograph, https://doi.org/10.22740/kdi.rm.2019.03.

McCarty, Nolan, Keith T. Poole, and Howard Rosenthal. 2006. Polarized America: The Dance of Ideology and Unequal Riches. Cambridge: MIT Press.

McDonald, Scott, and Michael Ramscar. 2001. "Testing the Distributional Hypothesis: The Influence of Context on Judgements of Semantic Similarity." Twenty-third Annual Conference of the Cognitive Science Society, 1-4 August 2001, Edinburgh, Scotland.

Mikolov, Tomas, Kai Chen, Greg Corrado, and Jeffrey Dean. 2013. "Efficient Estimation of Word Representations in Vector Space.” arXiv: 1301.3781.

Min, Hee, and Seongyi Yun. 2018. "Selective Exposure and Political Polarization of Public Opinion on the Presidential Impeachment in South Korea: Facebook vs. KakaoTalk." Korea Observer 49 (1): 137-159.

Moon, Woojin. 2005. "Decomposition of Regional Voting in South Korea: Ideological Conflicts and Regional Interests." Party Politics 11 (4): 579-599.

Oh, Young-jin. 2019. "You don't represent us." The Korea Times, October 4, www.koreatimes.co.kr/www/ opinion/2019/10/667_276627.html (accessed April 20, 2021).

Pantel, Patrick. 2005. "Inducing Ontological Co-occurrence Vectors." Proceedings of the 43th Conference of the Association for Computational Linguistics, 25-30 June 2005, Morristown, New Jersey.

Park, Yun-Hee, Min-Su Kim, Won-ho Park, Shin-Goo Kang, and Bon Sang Koo (박윤희 김민수 박원호 강신구 구본상). 2016. “제20대 국회의원선거 당선자 및 후보자의 이념성향과 정책태도” [Ideology and Policy Positions of the Candidates and the Elects in the 20th Korean National Assembly Election]. 의정연구 [Korea Journal of Legislative Studies] 22 (3): 117-158.

Pennington, Jeffrey, Richard Socher, and Christopher D. Manning. 2014. "GloVe: Global Vectors for Word Representation." 2014 Conference on Empirical Methods in Natural Language Processing, October 25-29, 2014, Doha, Qatar.

Peters, Matthew E., Mark Neumann, Mohit Iyyer, Matt Gardner, Christopher Clark, Kenton Lee, and Luke Zettlemoyer. 2018. "Deep Contextualized Word Representations." NAACL, June 1-6, New Orleans.

Pew Research Center. 2017. The Partisan Divide on Political Values Grows Even Wider: Sharp Shifts among Democrats on Aid to Needy, Race, Immigration. Washington DC: Pew Research Center.

Poole, Keith T. 2007. "Changing Minds? Not in Congress!” Public Choice 131 (3-4): 435-451.

Poole, Keith T., and Howard Rosenthal. 1985. "A Spatial Model for Legislative Roll Call Analysis." American Journal of Political Science 29 (2): 357-384.

- 1997. Congress: A Political-Economic History of Roll Call Voting. New York: Oxford University Press.

Pozen, David E., Eric L. Talley, and Julian Nyarko. 2019. "A Computational Analysis of Constitutional Polarization." Cornell Law Review 105: 1-84. 
Proksch, Sven-Oliver., Will Lowe, Jens Wackerle, and Stuart Soroka. 2019. "Multilingual Sentiment Analysis: A New Approach to Measuring Conflict in Legislative Speeches." Legislative Studies Quarterly 44 (1): 97-131.

Reijven, Menno H., Sarah Cho, Matthew Ross, and Gonen Dori-Hacohen. 2020. "Conspiracy, Religion, and the Public Sphere: The Discourses of Far-Right Counterpublics in the U.S. and South Korea." International Journal of Communication: 14, https:/ijoc.org/index.php/ijoc/article/view/13385.

Robison, Joshua, and Kevin J. Mullinix. 2016. "Elite Polarization and Public Opinion: How Polarization Is Communicated and Its Effects." Political Communication 33 (2): 261-282.

Sahlgren, Magnus. 2008. "The Distributional Hypothesis." Rivista di Linguistica 20 (1): 33-53.

Schwarz, Daniel., Denise Traber, and Kenneth Benoit. 2017. "Estimating Intra-Party Preferences: Comparing Speeches to Votes." Political Science Research and Methods 5(2): 379-393.

Seo, Hyun-Jin (서현진). 2016. “국회 갈등과 신뢰도에 관한 연구” [Party Support and Political Trust in Korean National Assembly]. 분쟁해결연구 [Dispute Resolution Studies Review] 14 (2): 159-184.

Shin, Gi-Wook, and Rennie J. Moon. 2017. "South Korea After Impeachment." Journal of Democracy 28 (4): 117-131.

Shor, Boris, and Nolan McCarty. 2011. "The Ideological Mapping of American Legislatures." American Political Science Review 105 (3): 530-551.

Sinclair, Barbara. 1982. Congressional Realignment 1925-1978. Austin: University of Texas Press

- 2000. "Hostile Partners: The President, Congress, and Lawmaking in the Partisan 1990s." In Polarized Politics: Congress and the President in a Partisan Era, edited by Jon R. Bond, and Richard Fleisher. Washington DC: CQ Press.

Singer, Matthew. 2016. "Elite Polarization and the Electoral Impact of Left-Right Placement: Evidence Latin America, 1995-2009." Latin America Research Review 51 (2): 174-194.

Statistics Korea. 2020. "2019 Korea's Social Indicators.” www.kostat.go.kr/portal/korea/kor_nw/1/1/index. board?bmode=read\&aSeq=383171 (accessed April 10, 2021).

Tenny, Ian, Dipanjan Das, and Ellie Pavlick. 2019. "BERT Rediscover the Classical NLP Pipeline." arXic: 1905.05950v2.

Theriault, Sean M. 2008. Party Polarization in Congress. New York: Cambridge University Press.

Vachudova, Milada A. 2019. From Competition to Polarization in Central Europe: How Populists Change Party Systems and the European Union. Polity 51 (4): 689-706.

Wilkerson, John, and Andreu Casas. 2017. "Large-Scale Computerized Text Analysis in Political Science: Opportunities and Challenges." Annual Review of Political Science 20: 529-544.

Wu, Yonghui, Mike Schuster, Zhifeng Chen, Quoc V. Le, Mohammad Norouzi, Wolfgang Macherey, Maxim Krikun, Yuan Cao, Qin Gao, Klaus Macherey, Jeff Klingner, Apurva Shah, Melvin Johnson. Xiaobing Liu, Łukasz Kaiser, Stephan Gouws, Yoshikiyo Kato, Taku Kudo, Hideto Kazawa, Keith Stevens, George Kurian, Nishant Patil, Wei Wang, Cliff Young, Jason Smith, Jason Riesa, Alex Rudnick, Oriol Vinyals, Greg Corrado, Macduff Hughes, Jeffrey Dean. 2016. "Google's Neural Machine Translation System: Bridging the Gap between Human and Machine Translation." arXiv: 1609.08144 .

Yoo, Sung Jin (유성진). 2009. "국회의 사회통합기능과 국민의 신뢰: 국회에 대한 기대와 현실의 괴리" [National Assembly as a Representative Institution and Public Trust: Gap between Expectation and Reality]. 의정연구 [Korean Journal of Legislative Studies] 27: 119-144.

\section{Appendix A}

In natural language processing (NLP), "distribution" refers to a set of neighboring words or contexts that appear simultaneously within a window, that is, within a specific range. The distribution of individual words depends mainly on where within sentences the words appear and which words appear frequently in neighboring positions (Harris 1954; McDonald and Ramscar 2001; Sahlgren 2008). That is, NLP is premised on a distributional hypothesis (Pantel 2005): if a word pair appears frequently in a similar context, the meaning of the words will also be similar.

Conventional statistics-based language models are trained by counting the frequency of words; in contrast, neural network learning enables flexible capture of the relationship between input and output and can function as a probability model in itself (Goldberg 2017). A neural network, which belongs to machine 
learning, is a series of algorithms that endeavors to recognize underlying relationships in a set of data through a process that mimics the way the human brain operates. In this sense, neural networks refer to systems of neurons, either organic or artificial in nature. Among NLP models using neural networks, this study applies BERT, a transformer-based transfer learning model that uses contextual information embedded at the sentence level and combines supervised and unsupervised learning with bidirectional characteristics that accounts for both forward and reverse directional contexts (Devlin et al. 2019). This model was published by Google in 2018.

The reason why this study uses BERT as a text classification model lies in its embedding and tokenization methods. First is dynamic embedding (Peters et al. 2018; Devlin et al. 2019). Ideal expressions of words must contain the syntactic and semantic characteristics of the words and must capture meanings that can vary by context. Context-free models such as Word2Vec and GloVe, which embed at word level, have been limited in expressing words that shift by context, because in these models all words have static vectors (Mikolov et al. 2013; Pennington, Socher, and Manning 2014), and certain words always carry the same expression regardless of the situation.

A feature of BERT that most prominently distinguishes it from the conventional Word2Vec and GloVe is that one word may entail different embeddings depending on the shape and position of the characters, thereby removing ambiguity. Because BERT dynamically generates word vectors using contexts, it is possible to create different word expressions depending on context. Another characteristic of BERT that this study notes is the tokenization method. As the Korean language is an agglutinative language, the role of morphemes is more prominent than in English, for example, and that of words less so. Hence, conventional Korean NLP has generally been used to cut and tokenize Korean language data into morphemes (Lim 2019). Thus there exist methods to utilize external morpheme analyzers that provide favorable performance, but this approach is not only affected by the variable performance of morpheme analyzers but also prone to multiple out-of-vocabulary (OOV) occurrences in the Korean language, in which word forms vary extensively. Accordingly, this study examines alternative tokenization methods independent of morpheme analyzers.

BERT uses a tokenization algorithm called Word Piece that tokenizes without relying on external morpheme analyzers. Word Piece creates a token by collecting meaningful units frequently appearing in a word and expresses a word as a combination of sub words, enabling detailed expressions of its meaning (Wu et al. 2016; Devlin et al. 2019). This approach is useful for processing words not found in the dictionary, such as neologisms. The application of BERT Word Piece may be useful because the minutes of the subcommittee of the standing committee of the National Assembly, which this study analyzes, reflects various issues in diverse areas of real society.

In terms of performance, favorable performance of a model indicates that it captures the grammatical and semantic relationships of natural languages. Sentence embedding techniques such as BERT are useful in that they more effectively capture these relationships than word-level embedding techniques such as Word2Vec and GloVe. Furthermore, among models using sentence embedding techniques (ELMo, GPT), BERT actively utilizes the role of context, bidirectionally examining forward and reverse-directional contexts (Devlin et al. 2019; Tenny, Das, and Pavlick 2019). Similarly, Generative Pre-trained Transformer 2 (GPT-2) is an open-source artificial intelligence created by OpenAI in 2019, which is another transformer-based learning model (Ethayarajh 2019).

\section{Appendix B}

\section{B1 BERT NLP model learning code (Google Colab Python 3)}

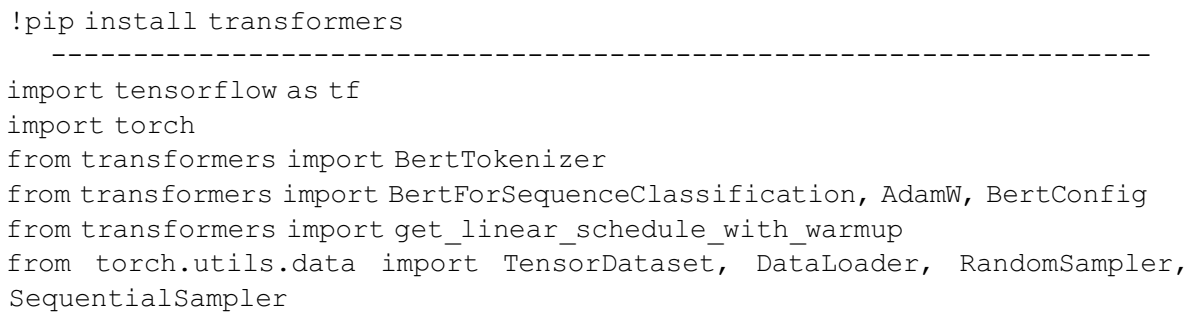


from keras.preprocessing.sequence import pad_sequences from sklearn.model_selection import train_test_split from sklearn.metrics import classification_report

import pandas as pd

import numpy as np

import random

import time

import datetime

Train $=$ pd.read_csv ('/content/train. Csv')

sentences $=$ train['text']

sentences[ : 5]

labels sentences $=[$ "[ CLS] " + str (sentence) + " [ SEP] " for sentence in sentences]

sentences[:5]

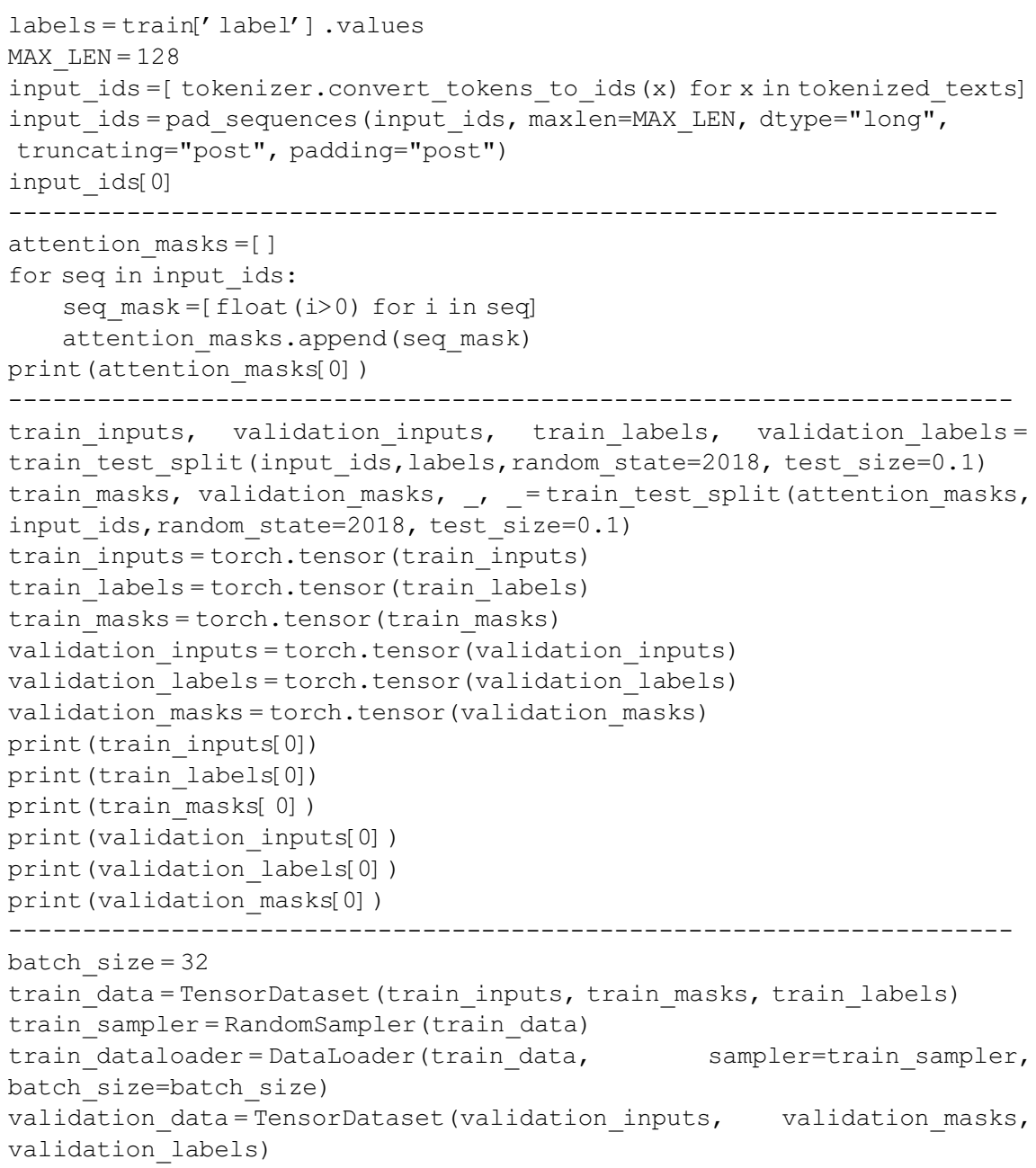


validation_sampler=SequentialSampler(validation_data)

validation_dataloader=DataLoader(validation_data, $\quad$ sampler=validation_sampler, batch_size=batch_size)

device_name=tf.test.gpu_device_name()

if device_name $==$ ' /device:GPU: $0^{\prime}$ :

print ('Found GPU at: \{\}$^{\prime}$. format (device_name)) else:

raise SystemError (' GPU device not found' )

if torch.cuda.is_available():

device=torch. device ("cuda")

print (' There are od GPU(s) available.' \% torch.cuda.device_count())

print (' We will use the GPU:', torch.cuda.get_device_name (0) ) else:

device=torch.device ("cpu")

print (' No GPU available, using the CPU instead.' )

model = BertForSequenceClassification.from_pretrained

("bert-base-multilingual-cased", num_labels=2)

model. cuda ()

optimizer = AdamW (model parameters (), lr $=2 e-5$, eps $=1 e-8)$

epochs $=3$

total steps = len (train dataloader) * epochs

scheduler=get_linear_schedule_with_warmup (optimizer, num_warmup_steps $=0$, num_training_steps $=$ total_steps)

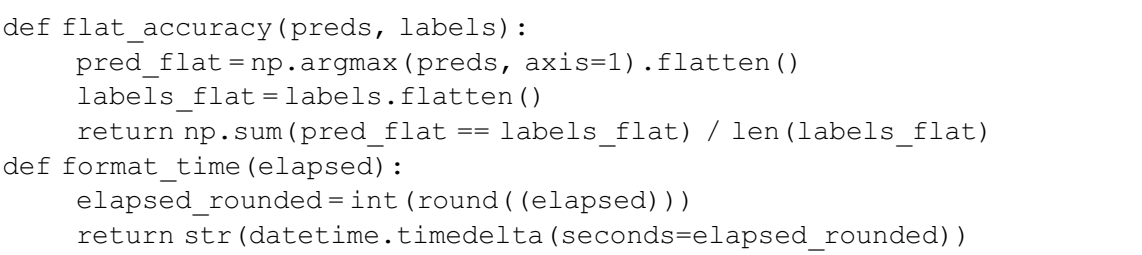

seed_val $=42$

random. seed ( seed val)

np.random. seed (seed val)

torch.manual seed (seed val)

torch.cuda.manual seed all (seed val)

model.zero grad ()

for epoch i in range (0, epochs):

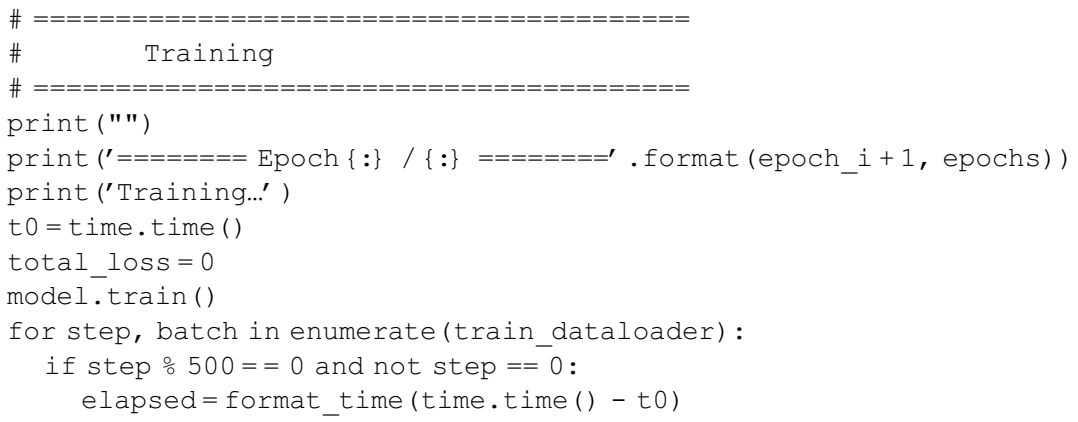




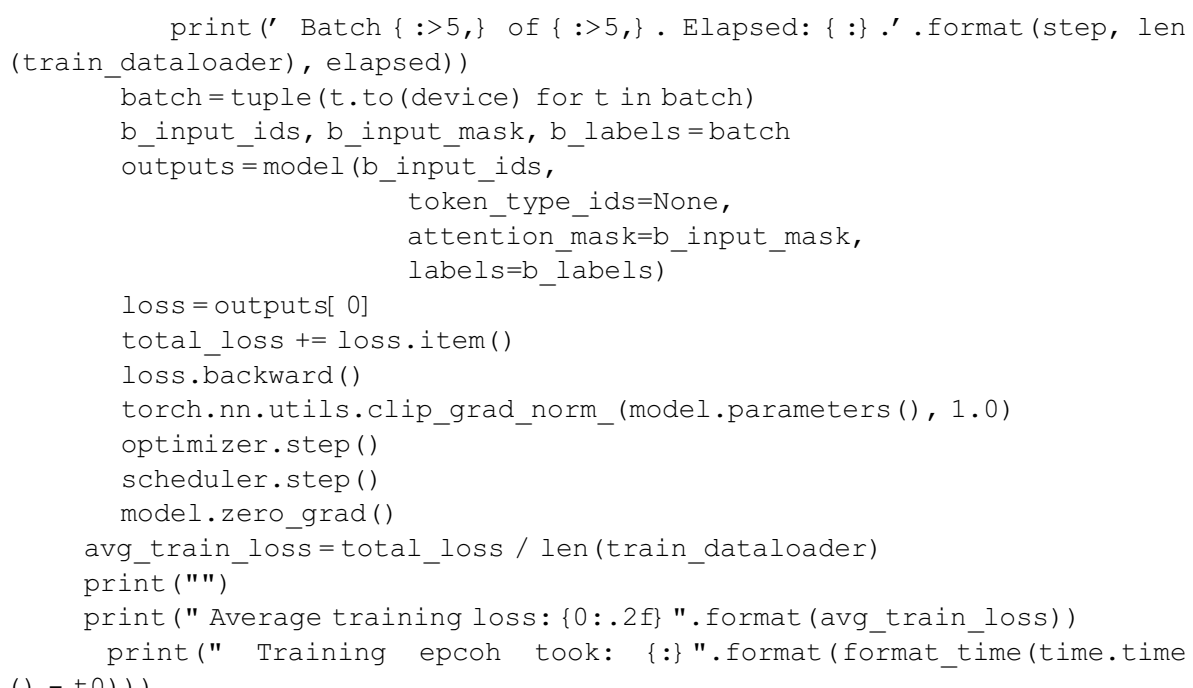
() $-\mathrm{t} 0)$ ))

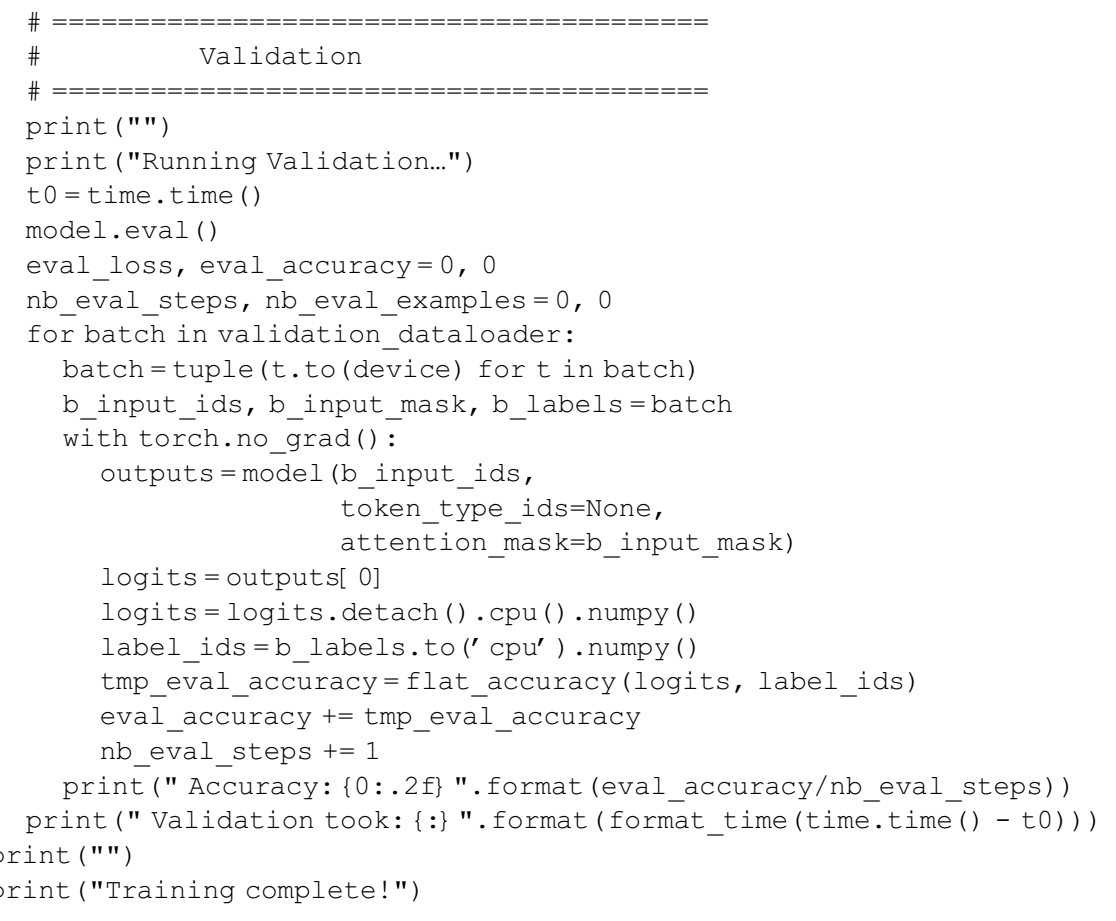

* The code above was programmed by the author for the analysis.

** The code above may change a little according to changes in the Google Colab environment.

*** A rigorous text preprocessing and labeling should be preceded prior to the implementation of the above process. 


\section{B2 BERT Test code (Google Colab Python 3)}

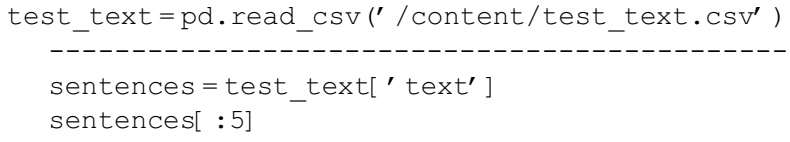


b_input_ids, b_input_mask, b_labels = batch

with torch.no_grad ():

outputs $=$ model (b_input_ids,

token_type_ids=None,

logits = outputs[ 0$]$ attention_mask=b_input_mask)

logits $=$ logits.detach (). cpu (). numpy()

label_ids =b_labels.to (' $\left.\mathrm{cpu} \mathbf{u}^{\prime}\right)$. numpy ()

tmp_eval_accuracy=flat_accuracy (logits, label_ids)

eval_accuracy $+=$ tmp_eval_accuracy

no_eval_steps $+=1$

print ("")

print ("Accuracy: \{0:.4f\}".format (eval_accuracy/nb_eval_steps))

print ("Test took: \{:\} ".format (format_time (time.time()-to)))

* The code above was programmed by the author for the analysis.

** The code above may change a little according to changes in the Google Colab environment.

*** A rigorous text preprocessing and labeling should be preceded prior to the implementation of the above process.

\section{B3 GPT-2 NLP model learning code (Google Colab Python 3)}

! wget https://raw.githubusercontent.com/NLP-kr/tensorflow-ml-nlp-tf2/ master/requirements. txt - O requirements.txt

!pip install -r requirements.txt

! pip install tensorflow $==2.2 .0$

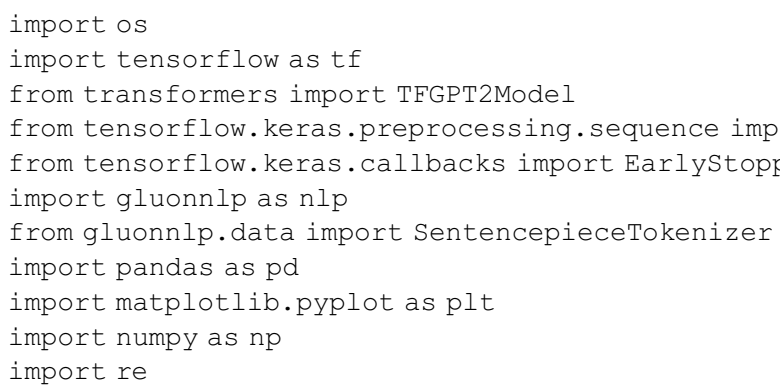


plt. show ()

SEED_NUM $=1234$

tf.random.set_seed (SEED_NUM)

np.random. seed (SEED_NUM)

TOKENIZER_PATH =' . /gpt_ckpt/gpt2_kor_tokenizer.spiece' tokenizer = SentencepieceTokenizer (TOKENIZER_PATH)

$\mathrm{vocab}=\mathrm{nlp}$. vocab.BERTVocab.from_sentencepiece (TOKENIZER_PATH, mask token=None, sep_token $=^{\prime}\langle$ unused0>' , cls_token=None, unknown_token $=^{\prime}\langle\text { unk }\rangle^{\prime}$, padding_token $=^{\prime}\langle\text { pad }\rangle^{\prime}$, bos token $=^{\prime}\langle s\rangle^{\prime}$, eos_token $=^{\prime}\left\langle/ s^{\prime}\right\rangle^{\prime}$ )

BATCH_SIZE $=32$

NUM EPOCHS $=3$

VALID SPLIT $=0.1$

SENT_MAX_LEN $=39$

def clean_text (sent):

sent_clean=re.sub ("[ 가-힣ㄱ-하 - I IIs]", "', sent)

return sent_clean

train_data_sents $=[$ ]

train_data_labels $=[$ ]

for train sent, train label in train data[ [' text', ' label']].values: train_tokenized text $=\operatorname{vocab}[$ tokenizer (clean_text (train_sent))] tokens $=[\operatorname{vocab}[\mathrm{vocab} . \mathrm{bos}$ token] $]$

tokens $+=$ pad_sequences ([train_tokenized_text],

SENT_MAX_LEN,

value=vocab[ $\mathrm{vocab} \cdot$ padding_token], padding $=^{\prime}$ post' ) . tolist ()[0]

tokens $+=$ [ vocab[ vocab.eos_token] ]

train_data_sents.append (tokens)

train_data_labels.append (train_label)

train_data_sents $=$ np.array (train_data_sents, dtype=np.int64)

train_data_labels=np.array (train_data_labels, dtype=np.int64)

class TFGPT2Classifier(tf.keras.Model):

def_init_(self, dir_path, num_class):

super (TFGPT2Classifier, self). _init

self.gpt2 = TFGPT2Model.from_pretrained(dir_path)

self.num_class $=$ num_class

(self.gpt2.config.summary_first_dropout)

self.classifier =tf.keras.layers.Dense (self.num_class,

kernel_initializer=tf.keras.initializers. TruncatedNormal

(stddev=self.gpt2.config.initializer_range), name="classifier")

def call (self, inputs) :

outputs = self.gpt2 (inputs)

pooled_output =outputs[ 0] [ : , -1]

pooled_output $=$ self.dropout (pooled_output)

logits=self.classifier(pooled_output) 
return logits

BASE_MODEL_PATH $={ }^{\prime}$./gpt_ckpt

cls_model $=$ TFGPT2Classifier(dir_path=BASE_MODEL_PATH, num_class=2)

optimizer=tf.keras.optimizers.Adam (learning_rate=6.25e-5)

loss $=$ tf. keras.losses.SparseCategoricalCrossentropy (from_logits=True) metric $=$ tf. keras.metrics.SparseCategoricalAccuracy (' accuracy' )

cls_model.compile (optimizer=optimizer, loss=loss, metrics=[metric] )

model_name = "tf2_gpt2_political polarization"

earlystop_callback=Earlystopping (monitor='val_accuracy' , min_delta= 0.0001 , patience $=2$ )

history=cls_model.fit (train_data_sents, train_data_labels, epochs=NUM_EPOCHS, batch_size=BATCH_SIZE, validation_split=VALID_SPLIT, callbacks=[ earlystop_calliback] )

* The code above was programmed by the author for the analysis.

** The code above may change a little according to changes in the Google Colab environment.

*** A rigorous text preprocessing and labeling should be preceded prior to the implementation of the above process.

\section{B4 GPT-2 Test code (Google Colab Python 3)}

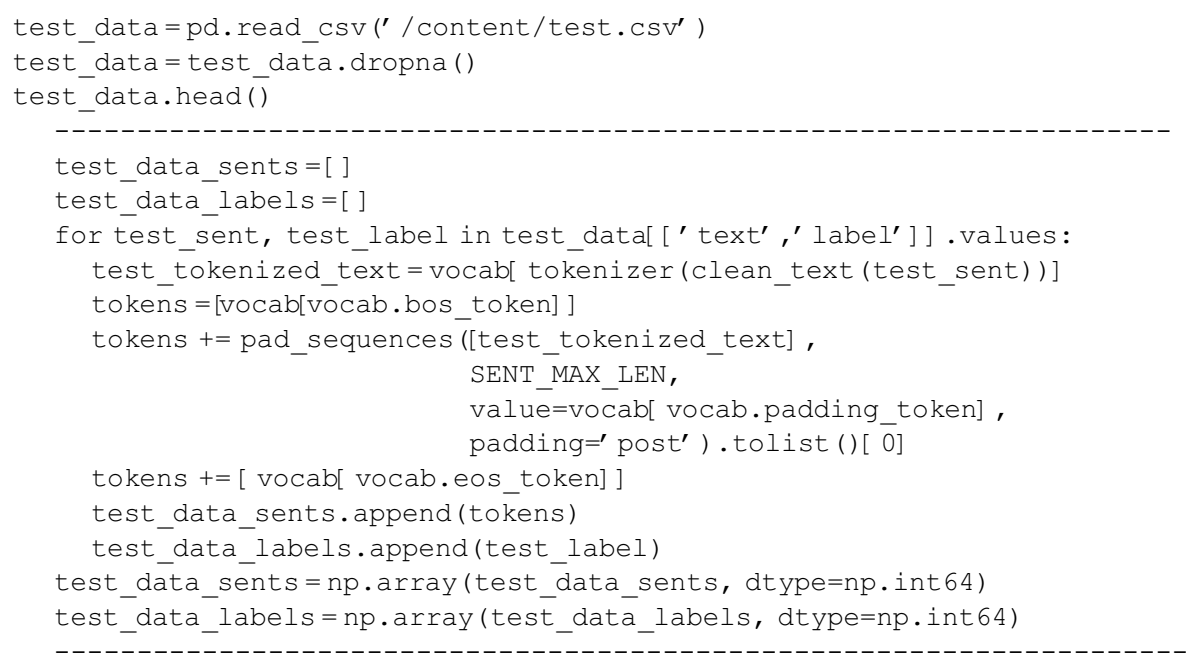


print ("test loss, test acc: ", results)

* The code above was programmed by the author for the analysis.

** The code above may change a little according to changes in the Google Colab environment.

*** A rigorous text preprocessing and labeling should be preceded prior to the implementation of the above process.

\section{Appendix C}

Table C1 16th National Assembly (May 30, 2000-May 29, 2004)

\begin{tabular}{lc}
\hline 0 & 1 \\
\hline The Millennium Democratic Party (59) & The Grand National Party (139) \\
\hline The Yeollin Uri Party (49) & The United Liberal Democrats (10) \\
\hline
\end{tabular}

Table C2 17th National Assembly (May 30, 2004-May 29, 2008)

\begin{tabular}{lc}
\hline 0 & 1 \\
\hline The United Democratic Party (136) & The Grand National Party (112) \\
\hline The Democratic Labor Party (6) & The Advancement Unification Party (9) \\
\hline The Creative Korea Party (1) & The Pro-Park Alliance (3) \\
\hline
\end{tabular}

Table C3 18th National Assembly (May 30, 2008-May 29, 2012)

\begin{tabular}{lc}
\hline 0 & 1 \\
\hline The United Democratic Party (81) & The Saenuri Party (165) \\
\hline The Unified Progressive Party (7) & The Advancement Unification Party (14) \\
\hline The Creative Korea Party (2) & The Korea Vision Party (1) \\
\hline
\end{tabular}

Table C4 19th National Assembly (May 30, 2012-May 29, 2016)

\begin{tabular}{lc}
\hline 0 & \multicolumn{1}{c}{ The Saenuri Party (145) } \\
\hline The Democratic Party of Korea (103) & \\
\hline The People's Party (20) & \\
\hline The Justice Party (5) & \\
\hline The Democratic Party (1)
\end{tabular}


Table C5 20th National Assembly (May 30, 2016-May 29, 2020)

\begin{tabular}{ll}
\hline 0 & \multirow{2}{*}{ The United Future Party (112) } \\
\cline { 1 - 1 } The Democratic Party of Korea (128) & \\
\hline The Minsaeng Party (20) & \multirow{2}{*}{ The Our Republican Party (1) } \\
\hline The Justice Party (6) & The Pro-Park New Party (1) \\
\hline The People's Party (1) &
\end{tabular}

Table C6 21st National Assembly (May 30, 2020-May 29, 2024)

\begin{tabular}{lc}
\hline 0 & The People Power Party (103) \\
\hline The Democratic Party of Korea (174) & \\
\hline The Justice Party (6) & The People Party (3) \\
\hline The Open Democratic Party (3) & \\
\hline The Basic Income Party (1) & \\
\hline
\end{tabular}

* Party classification is based on the second half of each National Assembly, excluding independent politicians. The boldface refers to the two major parties and the numbers in brackets refers to the number of seats.

\section{Appendix D}

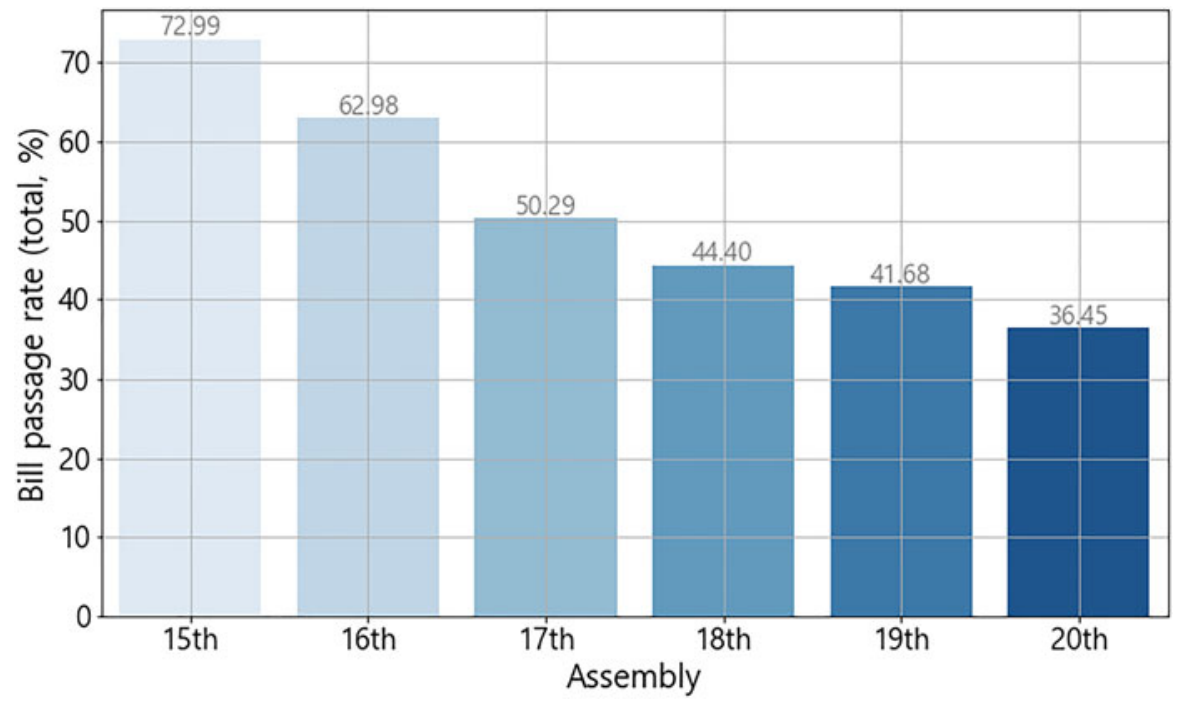

Figure D1. Bill passage rate, 15th National Assembly to 20th National Assembly Data from: Bill Information (https://likms.assembly.go.kr/bill/stat/statFinishBillSearch.do) 


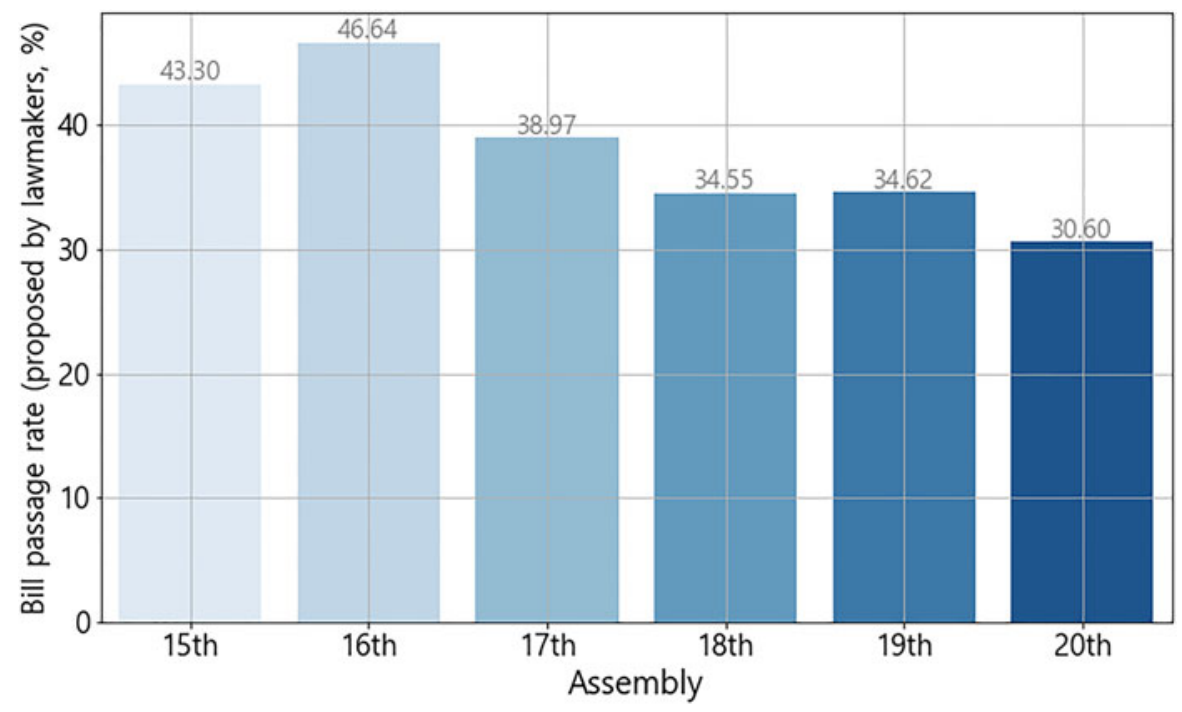

Figure D2. Bill passage rate (proposed by administrations), 15th National Assembly to 20th National Assembly

Data from: Bill Information (https://likms.assembly.go.kr/bill/stat/statFinishBillSearch.do)

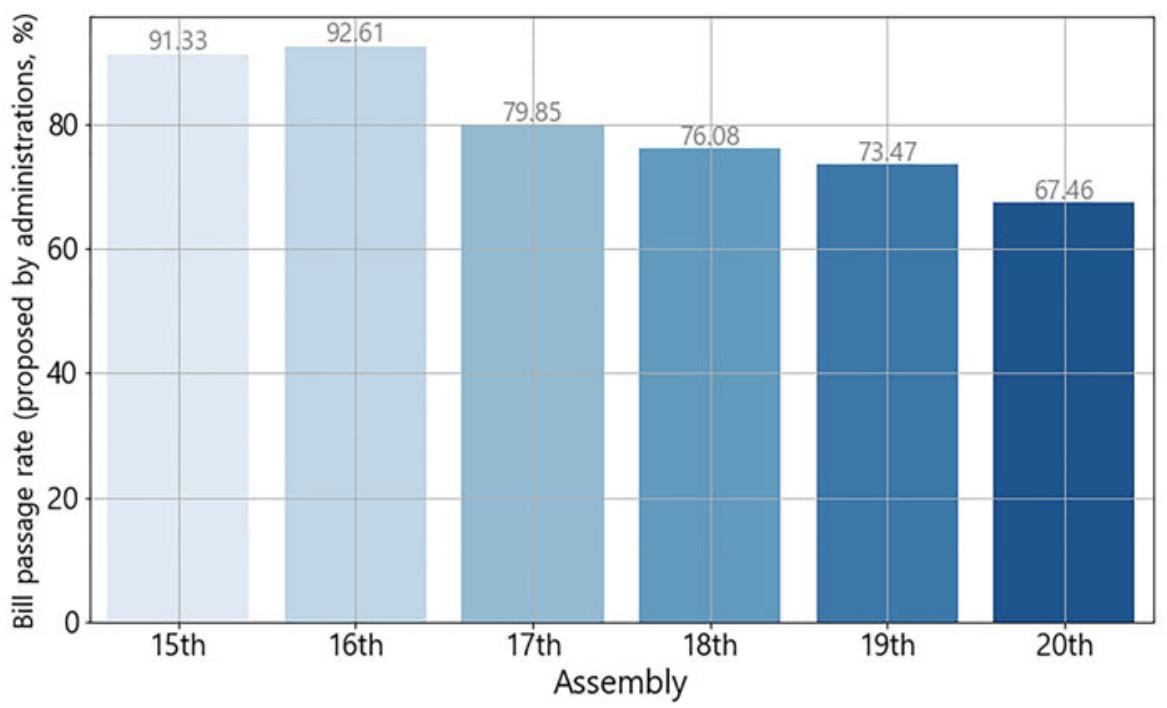

Figure D3. Bill repeal rate (proposed by administrations), 15th National Assembly to 20th National Assembly

Data from: Bill Information (https://likms.assembly.go.kr/bill/stat/statFinishBillSearch.do) 


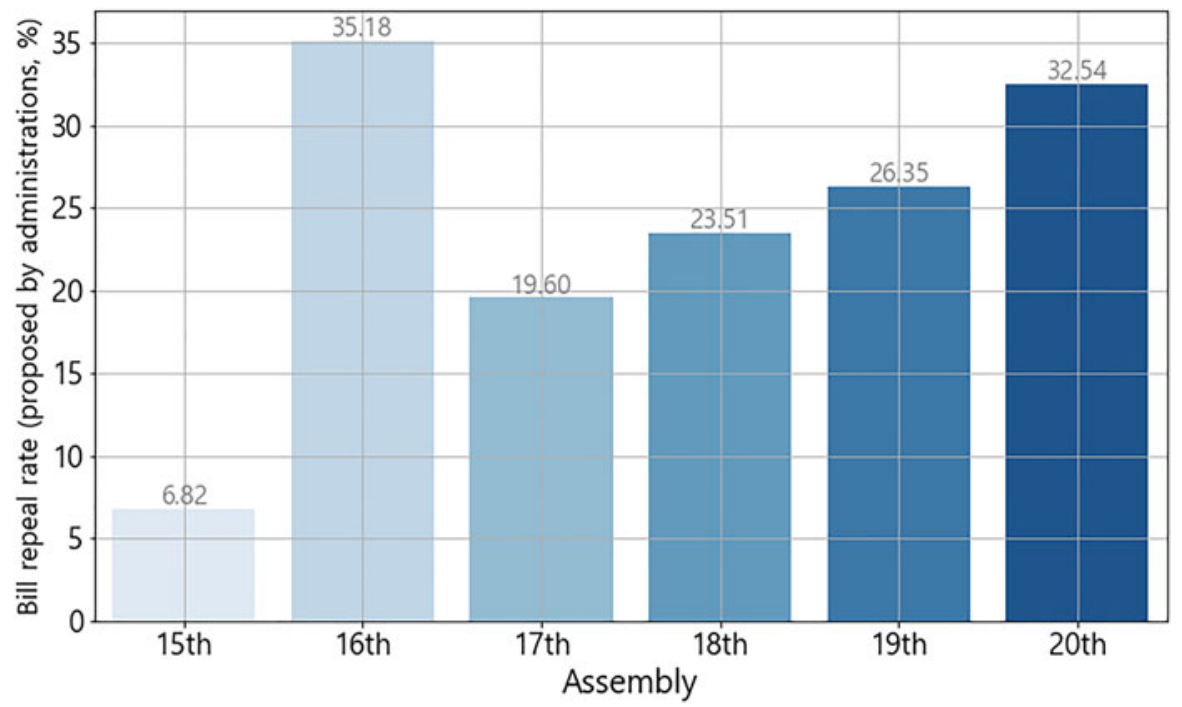

Figure D4. Bill passage rate (proposed by lawmakers), 15th National Assembly to 20th National Assembly

Data from: Bill Information (https://likms.assembly.go.kr/bill/stat/statFinishBillSearch.do)

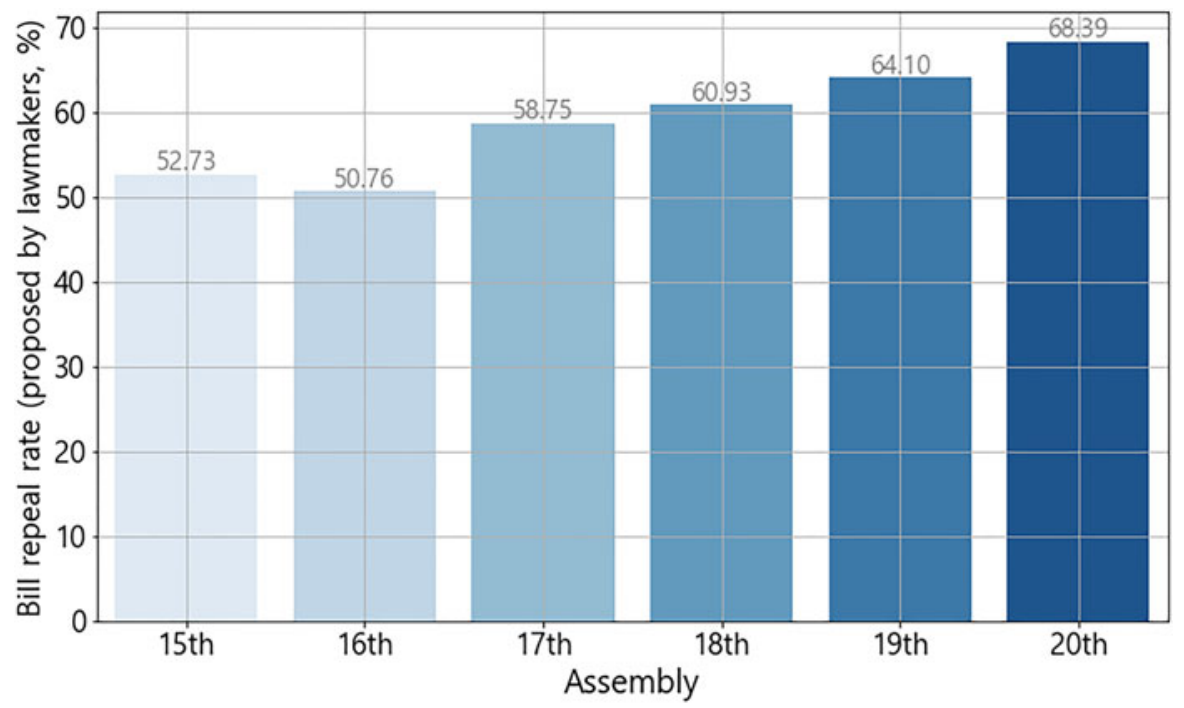

Figure D5. Bill repeal rate (proposed by lawmakers), 15th National Assembly to 20th National Assembly Data from: Bill Information (https://likms.assembly.go.kr/bill/stat/statFinishBillSearch.do) 
Seungwoo Han (seungwoo.han@rutgers.edu) is a Ph.D. candidate at Rutgers University, The State University of New Jersey. His research interests include comparative political economy, inequality, political behavior, social polarization, and welfare state. For the analysis, he is specialized in quantitative methods such as econometrics, Big Data, machine learning, neural networks, natural language processing and computer vision.

Cite this article: Han S (2022). Elite Polarization in South Korea: Evidence from a Natural Language Processing Model. Journal of East Asian Studies 22, 45-75. https://doi.org/10.1017/jea.2021.36 